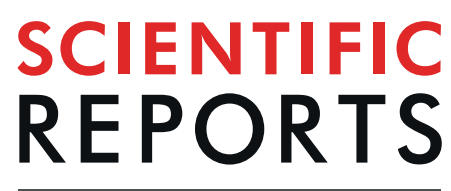

\title{
BACE1 partial deletion induces synaptic plasticity deficit in adult mice
}

\author{
Sylvia Lombardo ${ }^{1,2}$, Martina Chiacchiaretta ${ }^{2}$, Andrew Tarr ${ }^{3}$, WonHee Kim ${ }^{1,2}$, Tingyi Cao ${ }^{1,2}$, \\ Griffin Sigal ${ }^{1,2}$, Thomas W. Rosahl ${ }^{4}$, Weiming Xia ${ }^{5,6}$, Philip G. Haydon ${ }^{2}$, \\ Matthew E. Kennedy $\mathbb{D}^{7}{ }^{7}$ \& Giuseppina Tesco ${ }^{1,2^{*}}$
}

BACE1 is the first enzyme involved in APP processing, thus it is a strong therapeutic target candidate for Alzheimer's disease. The observation of deleterious phenotypes in BACE1 Knock-out (KO) mouse models (germline and conditional) raised some concerns on the safety and tolerability of BACE1 inhibition. Here, we have employed a tamoxifen inducible BACE1 conditional Knock-out (CKO) mouse model to achieve a controlled partial depletion of BACE1 in adult mice. Biochemical and behavioural characterization was performed at two time points: 4-5 months (young mice) and 12-13 months (aged mice). A $\sim 50 \%$ to $\sim 70 \%$ BACE1 protein reduction in hippocampus and cortex, respectively, induced a significant reduction of BACE1 substrates processing and decrease of $A \beta x-40$ levels at both ages. Hippocampal axonal guidance and peripheral nerve myelination were not affected. Aged mice displayed a CA1 long-term potentiation (LTP) deficit that was not associated with memory impairment. Our findings indicate that numerous phenotypes observed in germline BACE1 KO reflect a fundamental role of BACE1 during development while other phenotypes, observed in adult CKO, may be absent when partially rather than completely deleting BACE1. However, we demonstrated that partial depletion of BACE1 still induces CA1 LTP impairment, supporting a role of BACE1 in synaptic plasticity in adulthood.

Alzheimer's disease (AD) is the most common type of dementia characterized by loss of memory and degradation of cognitive function. A key neuropathological event in $\mathrm{AD}$ aetiology is the accumulation of the amyloid- $\beta$ $(\mathrm{A} \beta)$ peptide that originates from serial proteolysis of the amyloid precursor protein (APP). $\beta$-secretase, known as $\beta$-site APP cleaving enzyme 1 (BACE1), is the first enzyme involved in APP processing ${ }^{1-6}$. Thus, inhibiting $\mathrm{BACE} 1$ pharmacologically is a rational strategy for $\mathrm{AD}$ treatment ${ }^{7-10}$. Although BACE1 inhibition seems promising, many studies identified multiple phenotypes in germline BACE1 knock-out (BACE1 $1^{-1-}$ ) mice such as axon guidance defects ${ }^{11,12}$, hypomyelination ${ }^{13,14}$, increased astrogenesis ${ }^{15}$, sensorimotor gating impairment ${ }^{16}$ and memory impairment ${ }^{17}$. While these findings shed some light on BACE1 function, they also raise concerns about the possible side effects of therapeutic BACE1 inhibition in AD patients. The observation that BACE1 expression level is highest during postnatal development in mice and decreases with age ${ }^{13}$ lead to the hypothesis that the phenotypes observed in the BACE1 ${ }^{-1-}$ mice were caused by BACE1 function during development. Thus, BACE1 inhibition could be tolerated in adulthood. In addition, BACE1 KO in a mouse model of AD led to suppression of $\mathrm{AD}$ pathology and prevented cognitive impairment ${ }^{17,18}$.

To investigate the consequences of BACE1 inhibition in adulthood, conditional models (cKO) of BACE1 were recently developed ${ }^{19,20}$. These studies showed that BACE1 depletion in adult mice reverses amyloid deposition by reducing the amount of plaques in $5 x F A D$ mice. However, an almost total BACE1 depletion (mimicking pharmacological inhibition at high doses) was shown to induce LTP and axonal guidance defects ${ }^{19,20}$. It is worth mentioning that both cited studies achieved an almost total depletion of BACE1 protein in the adult mice. We

\footnotetext{
${ }^{1}$ Alzheimer's Disease Research Laboratory, Department of Neuroscience, Tufts University School of Medicine, Boston, Massachusetts, 02111, USA. ²Department of Neuroscience, Tufts University School of Medicine, Boston, Massachusetts, 02111, USA. ${ }^{3}$ Circuits and Behaviour Core, Center for Neuroscience Research, Tufts University School of Medicine, Boston, Massachusetts, 02111, USA. " External In Vivo Pharmacology, Merck \& Co. Inc., Kenilworth, NJ, 07033, USA. ${ }^{5}$ Geriatric Research, Education and Clinic Center, Bedford Veterans Affairs Medical Center, Bedford, MA, 01730, USA. ${ }^{6}$ Department of Pharmacology and Experimental Therapeutics, Boston University School of Medicine, Boston, MA, 02118, USA. ${ }^{7}$ Department of Neuroscience, Merck \& Co. Inc, Boston, MA, 02115, USA. *email: giuseppina.tesco@tufts.edu
} 
hypothesized that a lower level of BACE1 depletion may not result in negative phenotypes while still eliciting inhibition of CNS A $\beta$. To test this hypothesis, we achieved a partial deletion of BACE1 in a cKO mouse model and we characterized mice following both short-term acute depletion and long-term, prolonged depletion of BACE1. To do so, we treated mice BACE1 ${ }^{\text {flox/flox}}$;RosaCreERT2 ${ }^{+/ \text {WT }}$ with tamoxifen (TAM). Mice were characterized at two time points: 4-5 months (young) and 12-13 months (aged) corresponding to 1 and 10 months after cessation of TAM treatment respectively. In both investigated cohorts we detected reduced processing of multiple BACE1 substrates and a 50\% decrease in $\mathrm{A} \beta \mathrm{x}-40$ levels. Hippocampal axonal guidance and peripheral nerve myelination were not affected, however in aged mice we observed an LTP deficit in the CA1 region of the hippocampus that was not associated with a memory impairment in the behavioural tests investigated (Y maze and contextual fear conditioning).

Our findings indicate that many of the phenotypes observed in $\mathrm{BACE} 1^{-/-}$mice reflect a fundamental role of BACE1 during development while other phenotypes, observed in adult $\mathrm{cKO}$, may be absent when partially rather than completely inhibiting BACE1. However, we demonstrated that a partial depletion of BACE1 still induces CA1 LTP impairment, supporting a role of BACE1 in synaptic plasticity in adulthood.

\section{Results}

BACE1 is depleted in adult BACE1 cKO mice following tamoxifen treatment. To investigate the effects of BACE1 depletion in adult mice we generated a BACE1 cKO model. The Exon2 of BACE1 gene was flanked by loxP sites by homologous recombination (BACE1 $1^{\text {flox/flox }}$ ) (Supplementary Fig. 1a). Whole body inducible recombination was achieved by crossing the BACE1 $1^{\text {flox/flox }}$ line with the Rosa26CreERT2 line ${ }^{21}$ obtaining mice homozygous for BACE1 floxed allele and hemizygous for the Rosa26CreERT2 allele (BACE1 ${ }^{\text {flox/flox}}$; RosaCreERT2 ${ }^{+/ \mathrm{WT}}$ ) (Supplementary Fig. 1b). To induce recombination mice (between 8 and 12 weeks of age) were treated with $200 \mathrm{mg} / \mathrm{kg}$ per body weight of TAM or vehicle (VEH) over a 5 -week period consisting of 5 consecutive days of dosing in weeks 1, 3 and 5. Each treatment week was followed by a week of recovery (i.e. weeks 2 and 4; Fig. 1a). Mice were analysed at two different intervals (Fig. 1a), 4-5 month-old (young), corresponding to 1 month after treatment cessation and 12-13 month-old (aged), corresponding to 10 months after treatment. BACE1 mRNA levels were decreased in cortex, hippocampus and cerebellum of young TAM-treated mice compared to controls (Supplementary Fig. 2) (VEH-cortex:1; TAM-cortex:0.31; VEH-hippocampus:1, TAMhippocampus:0.50; VEH-cerebellum:1; TAM-cerebellum:0.32; expressed as fold-change; VEH $n=9$; TAM n =9; $\mathrm{p}<0.0001)$. BACE1 protein expression was decreased in young TAM-treated mice and differed in the areas investigated, $\sim 70 \%$ in cortex, $\sim 60 \%$ in hippocampus and $\sim 80 \%$ in cerebellum (Fig. 1b,c) (VEH-cortex: $1 \pm 0.05$; TAMcortex:0.35 \pm 0.04; VEH-hippocampus: $1 \pm 0.01$; TAM-hippocampus: $0.45 \pm 0.03$; VEH-cerebellum: $1 \pm 0.03$; TAM-cerebellum:0.19 $\pm 0.02 ; \mathrm{VEH} \mathrm{n}=8$, TAM $\mathrm{n}=8 ; \mathrm{p}<0.0001)$. Samples from BACE1 ${ }^{-1+}$ mice were also run for comparison with samples from TAM-treated mice. To establish whether TAM itself could affect BACE1 protein levels, we treated BACE1 $1^{\text {flox/flox }}$ mice (not carrying RosaCreERT2 allele) with the same protocol of drug administration (Fig. 1a) and euthanized them at 4-5 months of age (one month after the TAM treatment). Protein level of BACE1 were not altered in cortex of BACE $1^{\text {flox/flox }}$ TAM-treated compared to untreated WT mice, indicating that the decrease in BACE1 $1^{\text {flox/flox}}$;RosaCreERT2 ${ }^{+/ \text {WT }}$ was due to the recombination (Supplementary Fig. 3) (BACE1 $1^{\text {flox/flox: }} 0.91 \pm 0.03, \mathrm{n}=6$; WT: $1 \pm 0.08, \mathrm{n}=5$; $\mathrm{ns}$ ). Next, we determined BACE1 expression levels in aged mice. A significant reduction of BACE1 expression was observed: $~ 50 \%$ in cortex, $\sim 50 \%$ in hippocampus and $\sim 70 \%$ in cerebellum (Fig. 1d,e), (VEH-cortex: $1 \pm 0.03$; TAM-cortex:0.48 \pm 0.04 ; VEH-hippocampus: $1 \pm 0.05$; TAM-hippocampus:0.48 \pm 0.06 ; VEH-cerebellum: $1 \pm 0.04$; TAM-cerebellum:0.29 \pm 0.04 ; VEH $\mathrm{n}=7$; TAM $\mathrm{n}=7$; $\mathrm{p}<0.0001$ ). Immunohistochemistry confirmed decreased levels of BACE1 in brain sections of TAM-treated mice compared to controls at both time points (Fig. 1f). Depletion of BACE1 did not affect the protein expression level of APP-metabolism related genes, ADAM Metallopeptidase Domain 10 (ADAM10) and Presenilin 1 (PS1), $\alpha$ and $\gamma$-secretase respectively (ADAM10: VEH: $1 \pm 0.01$, TAM:1.08 \pm 0.06 ; PS1: VEH: $1 \pm 0.03$, TAM:1.01 \pm 0.03 , $\mathrm{n}=8$; ns) (Supplementary Fig. 4).

BACE1-mediated processing of APP and CHL1 is reduced in both young and aged BACE1 CKO mice following tamoxifen treatment. Next, we investigated how reduced levels of BACE1 affected the processing of multiple substrates. Cortex homogenates of TAM- and VEH-treated mice were analysed. Western blot analysis showed an accumulation of APP-full length in young mice (APP-FL) (VEH:1 \pm 0.06 , $\mathrm{n}=7$; TAM:1.73 $\pm 0.11, \mathrm{n}=8 ; \mathrm{p}<0.001)$ (Fig. 2a,d) corresponding to decreased levels of phosphor-C89 (pC89) (VEH:1 $\pm 0.08, \mathrm{n}=8$; TAM:0.36 $\pm 0.05 \mathrm{n}=8$; $\mathrm{p}<0.0001$ ) and phosphor-C99 (pC99) (VEH: $1 \pm 0.09$, $\mathrm{n}=8$; TAM: $0.34 \pm 0.07, \mathrm{n}=8 ; \mathrm{p}<0.001$ ) (Fig. $2 \mathrm{~b}, \mathrm{~d}$ ). We then quantified the processing of CHL1, because of its high affinity for BACE ${ }^{22,23}$. CHL1-full length was accumulated in cortex homogenates (CHL1-FL) (Fig. 2c,d) (VEH: $1 \pm 0.03, \mathrm{n}=8$; TAM:1.97 $\pm 0.13, \mathrm{n}=8 ; \mathrm{p}<0.0001$ ), while levels of CHL1-N Terminal Fragment (CHL1-NTF) (Fig. 2c,d) (VEH: $1 \pm 0.08, \mathrm{n}=8$; TAM: $1.10 \pm 0.20, \mathrm{n}=8$; ns) were not affected consistent with $\mathrm{CH}-\mathrm{L} 1$ proteolysis by multiple sheddases. However, the overall processing of CHL1 was impaired as indicated by a decrease in the CHL1-NTF/CHL1-FL ratio (Fig. 2d) (VEH: $1 \pm 0.06, \mathrm{n}=8$; TAM:0.44 $\pm 0.04, \mathrm{n}=8$; $\mathrm{p}<0.0001)$. To further characterize BACE1 CNS activity following recombination we quantified the level of $A \beta x-$ 40 in cortical samples from VEH- or TAM-treated mice by ELISA. We observed $~ 50 \%$ decrease of A $\beta \mathrm{x}-40$ levels in TAM-treated mice (Fig. 2e) (VEH:2.712 $\pm 0.1506, \mathrm{n}=8$; TAM:1.237 $\pm 0.06744, \mathrm{pMol} / \mathrm{g}, \mathrm{n}=8 ; \mathrm{p}<0.0001$ ). The analysis of cortical samples collected from aged TAM-treated mice revealed comparable results. Briefly, APP-FL was increased (Fig. 3a,d) (VEH:1 $\pm 0.04, \mathrm{n}=7$; TAM:1.75 $\pm 0.08, \mathrm{n}=7 ; \mathrm{p}<0.0001$ ), corresponding to decreased levels of $\mathrm{pC} 89$ (VEH: $1 \pm 0.22, \mathrm{n}=7$; TAM:0.31 $\pm 0.08, \mathrm{n}=7 ; \mathrm{p}<0.05$ ) and $\mathrm{pC} 99$ (VEH: $1 \pm 0.07, \mathrm{n}=7$; TAM:0.37 $\pm 0.04, \mathrm{n}=7 ; \mathrm{p}<0.0001$ ) (Fig. 3b,d). CHL1 processing was also impaired as demonstrated by the accumulation of the CHL1-FL (Fig. 3c,d) (VEH:1 $\pm 0.07, \mathrm{n}=7$; TAM:2.35 $\pm 0.28, \mathrm{n}=7 ; \mathrm{p}<0.001$ ). Lower levels of CHL1-NTF were also observed in this cohort (Fig. 3a,d) (VEH: $\pm 0.09, \mathrm{n}=7$; TAM:0.56 $\pm 0.07, \mathrm{n}=7 ; \mathrm{p}<0.01$ ). 
(a)

Experimental Timeline

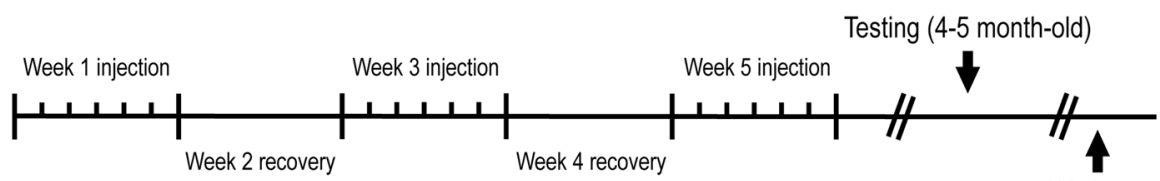

8 to 12 weeks old mice

BACE $^{\text {floxillox}} ;$ RosaCre $^{\text {ERT2+WT }}$

Testing (12-14 month-old)

(b)

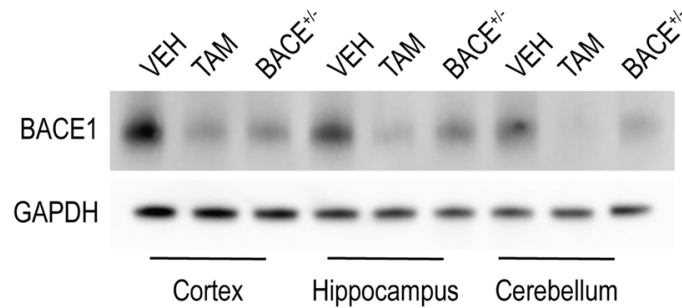

(c)

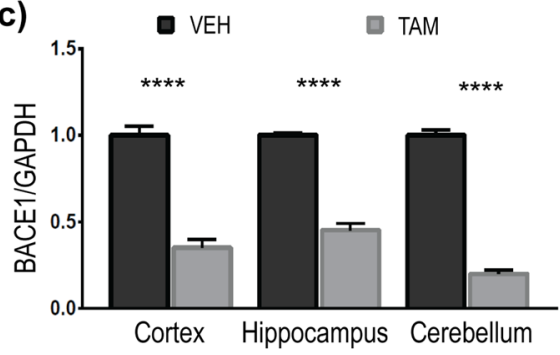

(f)

VEH
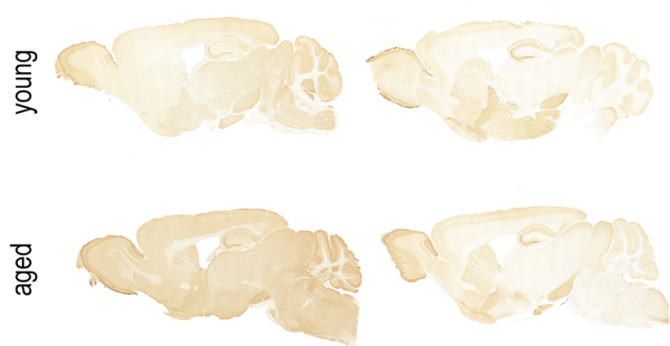

(d)

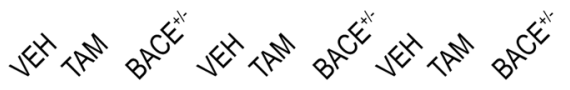

BACE1

GAPDH

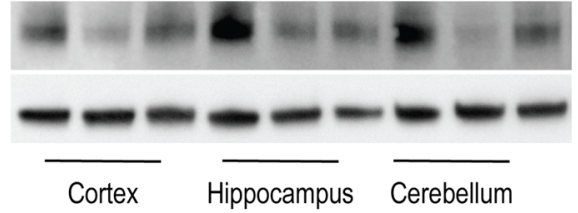

(e)

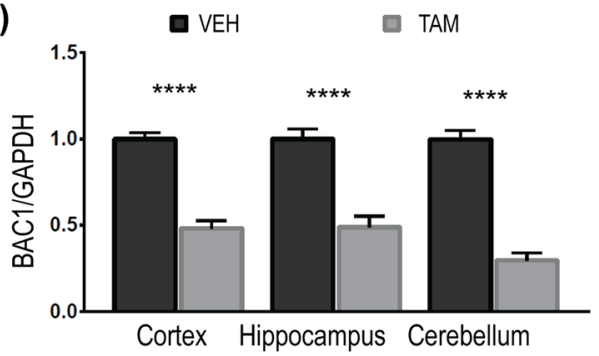

Figure 1. BACE1 is depleted in adult BACE1 cKO mice following tamoxifen treatment. (a) Experimental timeline showing treatment strategy used for tamoxifen or vehicle administration and time of experiments. Mice BACE1 $1^{\text {flox/flox}}$;RosaCreERT2 ${ }^{+/ W T}$ between 8 and 12 weeks of age were treated with a daily dose of $200 \mathrm{mg} / \mathrm{kg}$ of body weight of tamoxifen (TAM-treated) or vehicle (VEH-treated) for five consecutive days across five weeks of treatment, every week of injection being followed by a week of recovery. Mice were tested at two different time points: 4-5 (young) and 12-14 (aged) months of age. Brain homogenates from cortex, hippocampus or cerebellum of TAM- or VEH-treated mice were resolved by SDS-PAGE for Western blot analysis of BACE1 expression level (D10E5). Homogenates from aged-matched BACE1 ${ }^{+/-}$were also loaded as control samples (not included in densitometry analysis). GAPDH (MAB374) was used as loading control. Panels (b,d) are representative blots of TAM- or VEH-treated mice collected at 4-5 and 12-13 months of age respectively. (c) Densitometry analysis of protein expression. BACE1 levels were normalized to GAPDH and expressed as arbitrary unit (A.U.). Protein amount in TAM-treated mice was normalized to protein levels in control mice (set at 1). The percentage of BACE1 decrease in TAM-treated mice was: $\sim 70 \%$ in cortex, $\sim 60 \%$ in hippocampus and $\sim 80 \%$ in cerebellum in young mice $(\mathrm{VEH} \mathrm{n}=8$; TAM $\mathrm{n}=8)$. (e) Comparable results were observed in old mice (BACE1 decrease of $\sim 50 \%$ in cortex, $\sim 50 \%$ in hippocampus and $\sim 70 \%$ in cerebellum) (VEH $n=7$; TAM n $=7$ ). (f) Representative images of immunohistochemistry of sagittal sections of TAM- or VEH-traded mice collected at 4-5 (young) and 12-13 (aged) months of age showing decrease expression of BACE1 (EPR3956) in TAMtreated mice. Results were plotted as Mean \pm SEM, $* * * * p<0.0001$, Student's $t$ test. 
(a)

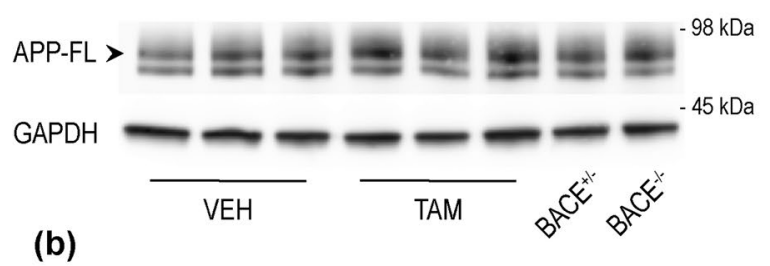

(b)

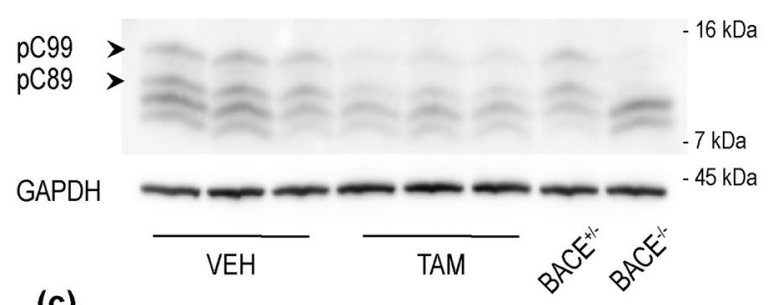

(c)

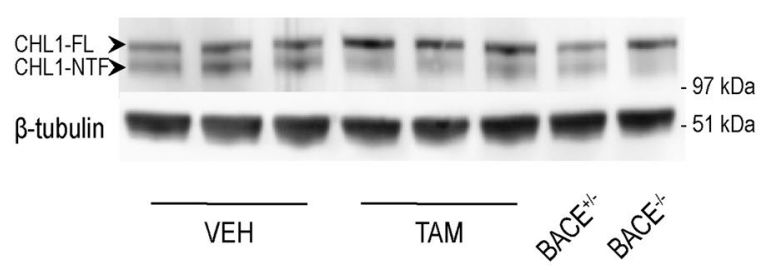

(d)

口 VEH

TAM

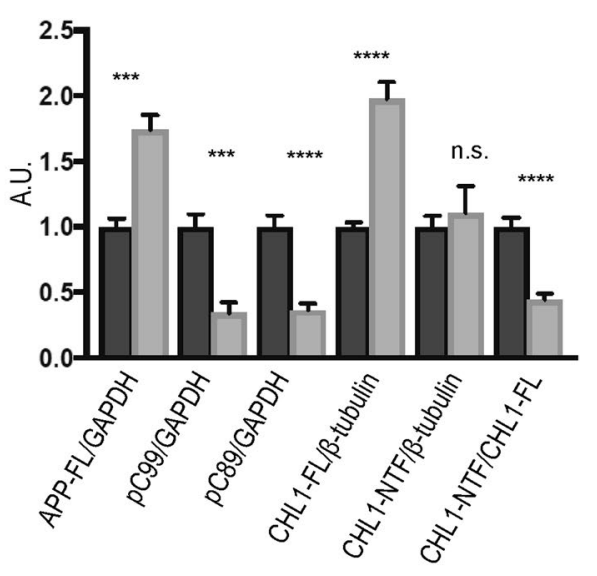

(e)

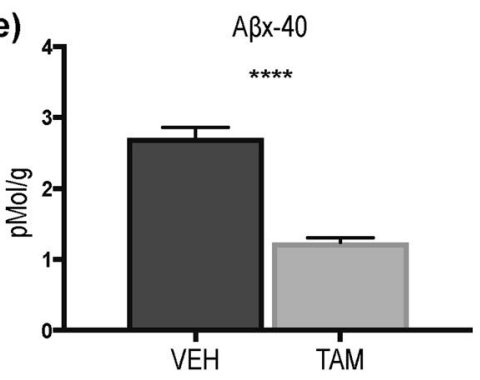

Figure 2. BACE1-mediated processing of APP and CHL1 is reduced in cortex of young BACE1 cKO mice following tamoxifen treatment. Cortex homogenates from TAM- or VEH-treated mice were resolved by SDSPAGE for Western blot analysis of APP and CHL1 processing. Homogenates from aged-matched $\mathrm{BACE}^{+/-}$and BACE $1^{-1-}$ were also loaded as control samples. Representative blots of (a) APP-full length (APP-FL) (C1/6.1), (b) APP-Carboxy Terminal Fragments (CTFs) (C1/6.1) and (c) CHL1. (d) Densitometry analysis of protein expression. Protein amount was normalized to protein levels in control mice (set at 1). APP-FL, pC99 and pC89 were normalized to GAPDH (MAB374) while CHL1-FL and CHL1-NTF were normalized to $\beta$-tubulin (JDR.3B8). APP processing was reduced in TAM-treated mice as demonstrated by the accumulation of APP-FL $(\mathrm{C} 1 / 6.1)$, and reduced levels of the $\beta C T F s$ pC99 and pC89. 3 CTFs were clearly identified because missing in the BACE1 $1^{-1-}$ sample. CHL1-FL (AF2147) levels were increased while CHL1-N Terminal Fragment (CHL1NTF) levels were not affected in cortex of TAM-treated mice. However, the CHL1-NTF/CHL1-FL ratio was significantly decreased in TAM-treated mice demonstrating reduced BACE1 processing (VEH $\mathrm{n}=8$; TAM $\mathrm{n}=8$ ). (e) $\mathrm{A} \beta \mathrm{x}-40$ was quantified from brain homogenates by ELISA (VEH $\mathrm{n}=8$; TAM $\mathrm{n}=8$ ). Levels of $\mathrm{A} \beta \mathrm{x}-40$ expressed as $\mathrm{pMol} / \mathrm{g}$ of cortex were significantly reduced in TAM-treated mice ( $\sim 50 \%$ decrease). Results were plotted as Mean \pm SEM, ${ }^{* * *} \mathrm{p}<0.001 ; * * * * \mathrm{p}<0.0001 ; \mathrm{n} . \mathrm{s}$. $=$ not significant, Student's $\mathrm{t}$ test.

$\mathrm{A} \beta \mathrm{x}-40$ quantified by MSD immunoassay was decreased in TAM-treated vs. VEH-treated mice ( $50 \%)$ (Fig. 3e) (VEH:0.42 $\pm 0.03, \mathrm{n}=7$; TAM:0.24 $\pm 0.01, \mathrm{pMol} / \mathrm{g}, \mathrm{n}=7 ; \mathrm{p}<0.01$ ).

Sciatic nerve myelination was not altered in young and aged BACE1 CKO mice following tamoxifen treatment. In light of the hypomyelination phenotype observed in $\mathrm{BACE} 1^{-1-}$ mice ${ }^{13,14}$ we quantified peripheral nerve myelination in our cohort of mice in which we achieved partial BACE1 depletion in adulthood. Sciatic nerves from young and aged mice TAM- or VEH-treated were collected. G-ratio quantification of electron microscopy images (Fig. 4a) was performed and no myelination deficit was observed in young (Fig. 4b) (Mann-Whitney $\mathrm{p}=0.61$, ns; Kolmogorov-Smirnov test $\mathrm{p}=0.7$, ns; VEH $\mathrm{n}=3$; TAM n $=3$ ) and aged mice treated with TAM (Fig. 4c) (Mann-Whitney $\mathrm{p}=0.85$, ns; Kolmogorov-Smirnov test $\mathrm{p}>0.99$, ns; VEH $\mathrm{n}=3$; TAM $\mathrm{n}=3$ ) indicating that the hypomyelination phenotype is most likely due to BACE1 activity during the development.

Normal axon guidance in hippocampus mossy fibers of aged BACE1 CKO mice following partial BACE1 deletion. Previous studies have shown that germline deletion of BACE1 results in axon guidance defects in the hippocampus and olfactory bulb ${ }^{12}$. Recently, Ou-Yang et al. ${ }^{19}$ reported the presence of the same phenotype in a BACE1 cKO model in which a $~ 90-95 \%$ depletion of BACE1 was achieved in cortex and hippocampus of 12 month-old mice. Thus, we performed a morphological study of the infrapyramidal bundle (IPB) in the hippocampus of aged TAM-treated mice in which BACE1 levels are $50 \%$ less than VEH-treated mice (Fig. 1). Brain sections from mice treated with VEH or TAM were immunostained with anti-synaptoporin (SPO) antibody (Fig. 5a) and the length of the IPB was measured (Fig. 5b). The length of the IPB was not altered 
(a)

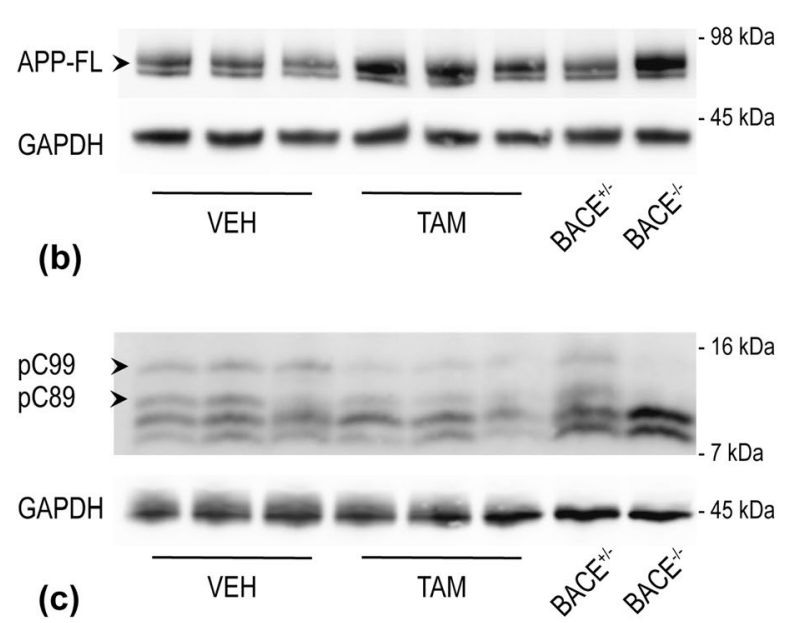

(c)

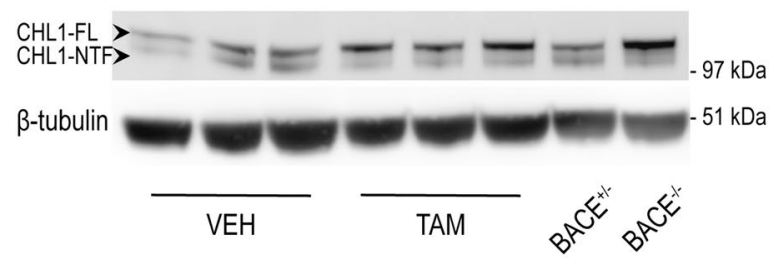

(d)

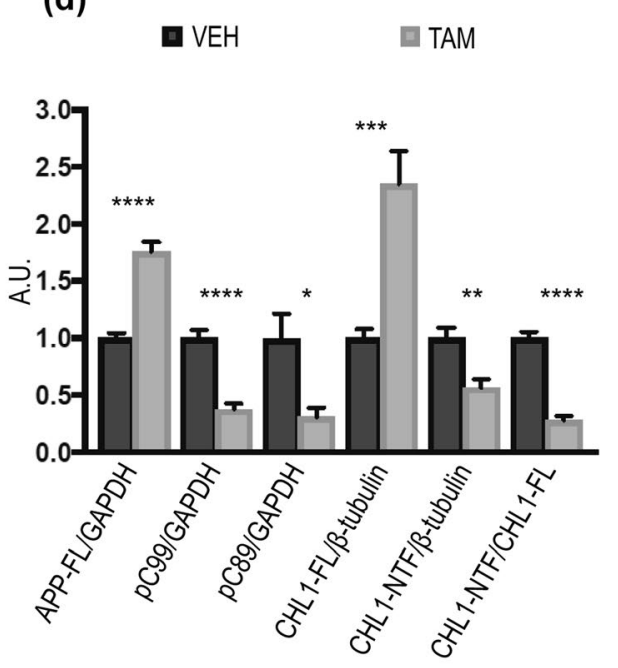

(e)

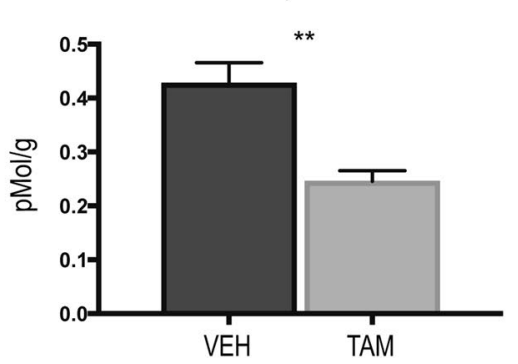

Figure 3. BACE1-mediated processing of APP and CHL1 is reduced in cortex of aged BACE1 cKO mice following tamoxifen treatment. Cortex homogenates from TAM- or VEH-treated mice were resolved by SDS-PAGE for Western blot analysis of APP and CHL1 processing. Homogenates from aged-matched $\mathrm{BACE}^{+/-}$and $\mathrm{BACE} 1^{-1-}$ were also loaded as control samples. APP-FL, pC99 and pC89 were normalized to GAPDH (MAB374) while CHL1-FL and CHL1-NTF were normalized to $\beta$-tubulin (JDR.3B8). Protein amount was normalized to protein levels in control mice injected with vehicle (set at 1). Representative blots of (a) APP-FL (C1/6.1), (b) APP-CTFs (C1/6.1) and (c) CHL1. (d) Densitometry analysis of protein expression. APP processing was reduced in TAM-treated mice as demonstrated by the accumulation of APP-FL (C1/6.1), and reduced levels of the $\beta C T F s$ pC99 and pC89. 3 CTFs were clearly identified because missing in the $\mathrm{BACE}^{-1-}$ sample. CHL1-FL (AF2147) levels were increased and CHL1-NTF levels were significantly reduced. Furthermore, the CHL1-NTF/CHL1-FL ratio was significantly decreased in TAM-treated mice demonstrating reduced BACE1 processing ( $\mathrm{VEH} n=7$; TAM $n=7$ ). (e) Quantification of $A \beta x-40$ was performed by MSD immunoassay on cortex homogenates and expressed as $\mathrm{pMol} / \mathrm{g}$ of cortex. The decrease of levels of $\mathrm{A} \beta \mathrm{x}-40$ in TAM-treated mice was comparable to the one observed in samples collected from young TAM-treated mice $(\sim 50 \%$ decrease $)($ VEH $n=7 ;$ TAM $n=7)$. Results were plotted as Mean \pm SEM, $* \mathrm{p}<0.05 ; * * \mathrm{p}<0.005$; $* * * \mathrm{p}<0.001 ; * * * * \mathrm{p}<0.0001 ;$ n.s. $=$ not significant, Student's t test.

in TAM-treated compared to VEH-treated mice (VEH:0.49 $\pm 0.01, \mathrm{n}=8$; TAM:0.50 $\pm 0.02, \mathrm{n}=7, \mu \mathrm{m}$ : IPB/ $\mathrm{MB}+$ slu; ns). Reduced BACE1 expression level in the hippocampus of TAM-treated mice was confirmed by immunostaining (Fig. 5c). As a control, brain sections of BACE1 $1^{-1-}$ mice were also stained. We confirmed the shortening of IPB in BACE1 $1^{-1-}$ mice (Supplementary Fig. 5). Next, we investigated the processing of BACE1 substrates in hippocampus homogenates from aged TAM- or VEH-treated mice. We observed an accumulation of APP-FL (VEH: $1 \pm 0.08, \mathrm{n}=7$; TAM:1.89 $\pm 0.18, \mathrm{n}=7 ; \mathrm{p}<0.001)$ and a decrease of the $\beta C T F s$ pC89 $(\mathrm{VEH}: 1 \pm 0.14, \mathrm{n}=7$; TAM:0.55 $\pm 0.05, \mathrm{n}=7 ; \mathrm{p}<0.05)$ and $\mathrm{pC} 99(\mathrm{VEH}: 1 \pm 0.06, \mathrm{n}=7$; TAM:0.53 $\pm 0.07, \mathrm{n}=7$; $\mathrm{p}<0.001$ ) (Fig. 5d). Since CHL1 processing impairment was previously associated to axon guidance defects ${ }^{12,24}$ we performed fractionation of hippocampus samples to achieve a better separation of CHL1-FL and CHL1-NTF. Membrane and soluble fractions (Fig. 5e) analysis revealed CHL1-FL accumulation (VEH:1 $\pm 0.08, \mathrm{n}=5$; TAM: $1.70 \pm 0.10, \mathrm{n}=5, \mathrm{p}<0.001$ ), while CHL1-NTF level was not affected in TAM-treated mice (VEH: $1 \pm 0.06$, $\mathrm{n}=5$; TAM: $1.00 \pm 0.13, \mathrm{n}=5$; ns) (Fig. $5 \mathrm{f}$ ). We then investigated levels of SEZ6, which is exclusively processed by BACE $1^{23,25}$. Membrane fraction analysis revealed SEZ6-FL accumulation (VEH: $1 \pm 0.09, \mathrm{n}=5$; TAM:1.47 \pm 0.05 , $\mathrm{n}=5 ; \mathrm{p}<0.01)$, decreased SEZ6-NTF levels in the soluble fraction $(\mathrm{VEH}: 1 \pm 0.07, \mathrm{n}=5$; TAM:0.48 \pm 0.05 , $\mathrm{p}<0.05, \mathrm{n}=5$ ) and decreased SEZ6-NTF/SEZ6-FL ratio (Fig. 5e,f). Moreover, TAM-treated mice displayed very low levels of APP soluble $\beta$ fragment $(\operatorname{sAPP} \beta)(\mathrm{VEH}: 1 \pm 0.26, \mathrm{n}=5$; TAM:0.04 $\pm 0.03, \mathrm{n}=5)$. A $\beta \mathrm{x}-40$ levels, quantified by MSD immunoassay, were found to be decreased in hippocampus of aged TAM-treated mice ( $~ 50 \%$ decrease) (Fig. 5g) (VEH:0.54 $\pm 0.05, \mathrm{n}=7$ TAM:0.29 $\pm 0.02, \mathrm{pMol} / \mathrm{g}, \mathrm{n}=7 ; \mathrm{p}<0.01$ ). 
(a)

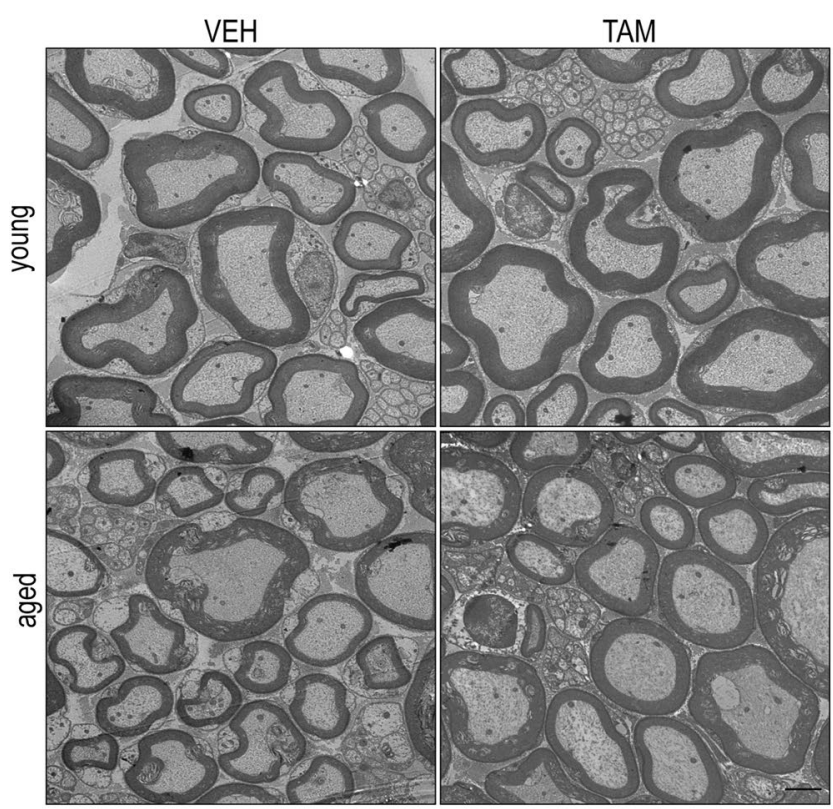

(b)

young

- VEH

口 TAM

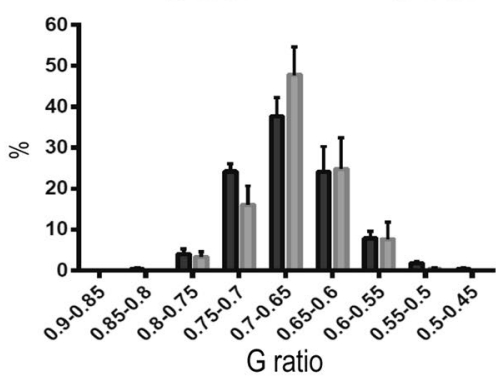

(c)

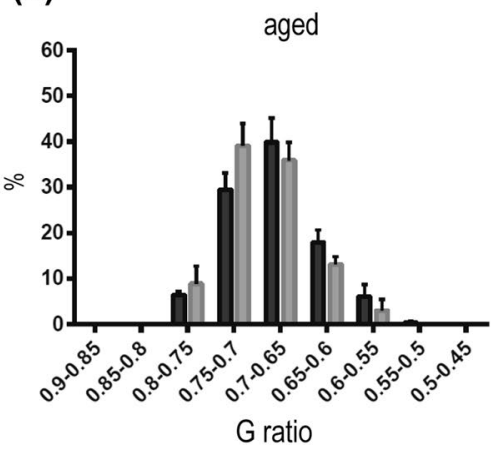

Figure 4. Sciatic nerve myelination was normal in young and aged BACE1 cKO mice following tamoxifen treatment. (a) Electron microscopy representative images of sciatic nerves from TAM- or VEH-treated mice, collected from 4-5 (upper panel) and 12-13 month (lower panel) old mice. Scale bar $2 \mu \mathrm{m}$. G-ratio analysis showed no myelination alteration in TAM-treated group compared to controls in young (b) or aged (c) mice (VEH $\mathrm{n}=3$; TAM $\mathrm{n}=3$, from 100 to 150 fibers were analyse from each mouse). Data were plotted as $\mathrm{g}$ ratio in function of fibers' frequency \pm SEM, Mann-Whitney test and Kolmogorov-Smirnov test.

LTP deficit is induced in aged BACE1 CKO mice following partial BACE1 depletion. Genetic deletion $^{17,26}$ and pharmacological inhibition of BACE1 in adult mice ${ }^{27}$, was shown to induce LTP deficit. However, whether LTP is impaired in cKO models remains controversial ${ }^{19,20}$. To address this question, field excitatory postsynaptic potentials (fEPSPs) were recorded in stratum radiatum in response to electrical stimulation of Shaffer Collateral fibers, in aged TAM- and VEH-treated mice. TAM-treated mice exhibited attenuated LTP in comparison to VEH-treated mice (VEH:132.1 $\pm 5.05, \mathrm{n}=12$ TAM:112.5 $\pm 0.1, \%$ from baseline, $\mathrm{n}=11 ; \mathrm{p}<0.05$ ) (Fig. 6a). LTP impairment was attributable to BACE1 partial depletion, since no deficit was observed in TAM-treated BACE $1^{\text {flox/flox }}$ (not expressing the RosaCre allele), compared to BACE $1^{\text {flox/flox }}$ uninjected controls (data not shown). Paired-pulse ratio (PPr), or input output curves were not affected, ruling out an effect on glutamate release probability and axonal excitability (Fig. 6b,c). These findings suggest that $~ 50 \%$ decrease of BACE1 protein in hippocampus is sufficient to affect synaptic plasticity, as detected by LTP impairment in the CA1 Shaffer collateral pathway.

No behavioural deficits were detected in young and aged cKO mice following partial BACE1 deletion. Finally, we performed a panel of behavioural experiments on young and aged mice focusing on behavioural phenotypes that were shown to be altered in $\mathrm{BACE}^{-1-}$ mice such as memory, pre-pulse inhibition (PPI), locomotion and anxiety ${ }^{16-18,28}$. Y-maze and contextual fear conditioning were performed to investigate spontaneous alteration and hippocampal dependent memory respectively. No memory deficits were observed in young or aged TAM-treated mice compared to controls (Fig. 7a,b; Supplementary Table 1). Deficits in sensory motor gating have been previously reported in BACE $1^{-1-}$ mice using the PPI task ${ }^{16}$. In this paradigm, a preceding low intensity tone (the pre-pulse) inhibits the reaction (startle response) to a higher intensity acoustic stimulus (the pulse). No deficit in TAM-treated mice was detected in both young and aged group when compared to VEH-treated mice (Fig. 7c,d; Supplementary Table 1). To assess locomotor activity and anxiety-like behaviour, mice were subjected to the open field test. The total distance travelled did not reveal any locomotor activity alteration in both young and aged groups; however, an effect of time was observed in male mice, aged male mice explored less (both TAM-treated and VEH-treated) compared to young male mice $(\mathrm{p}<0.001)$ (Fig. 7e; Supplementary Table 1). Analysis for exploration time of the open field revealed no difference between TAM- and VEH-treated mice at both ages (Fig. 7f; Supplementary Table 1). To further evaluate the anxiety-like behavioural phenotype, mice were subjected to the light/dark transitions task. No anxiety-like behavioural phenotype was observed in both young and aged TAM-treated mice (Fig. 7g; Supplementary Table 1). Taken together these data support the hypothesis that a partial depletion of BACE1 does not induced behavioural deficits in the investigated tasks after acute short-term depletion (young animals) or long-term depletion (aged animals). 
(a)

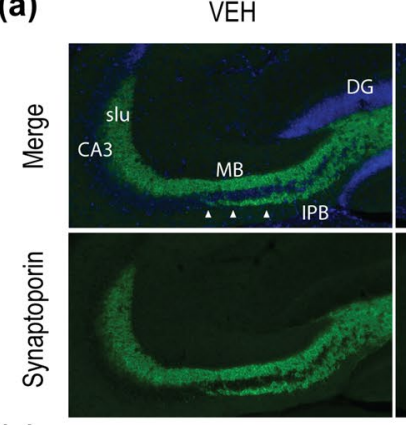

(c)

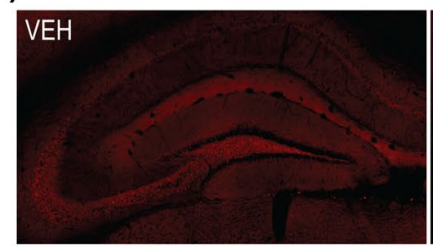

TAM

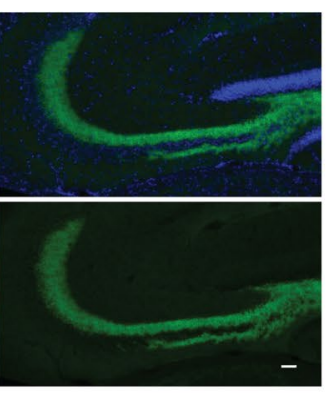

(b)

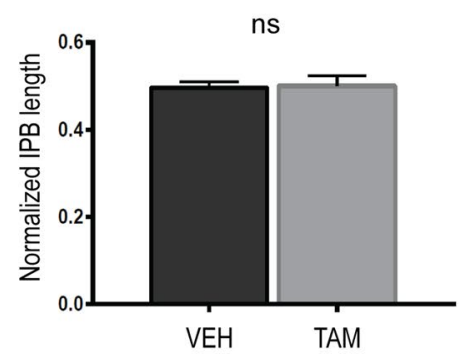

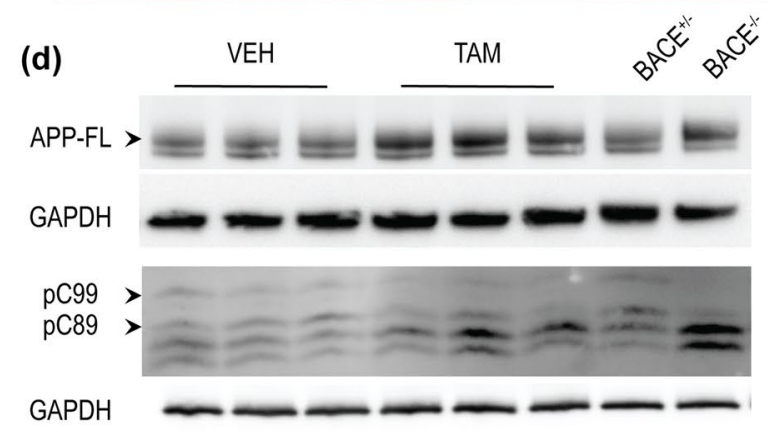
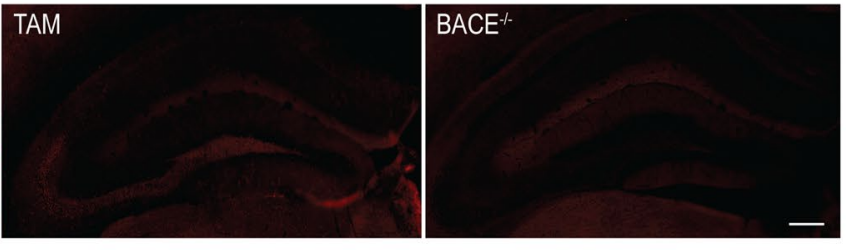

(d)
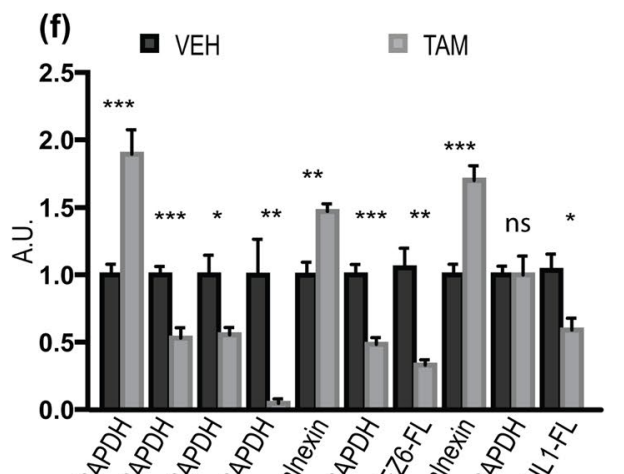

(f)

口 VEH

ㅁ TAM

(e)

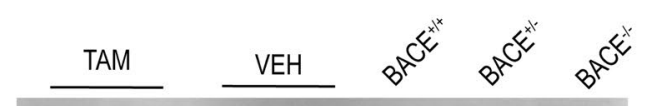

SEZ6-FL

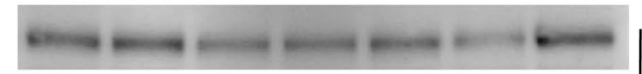

CHL1-FL > m
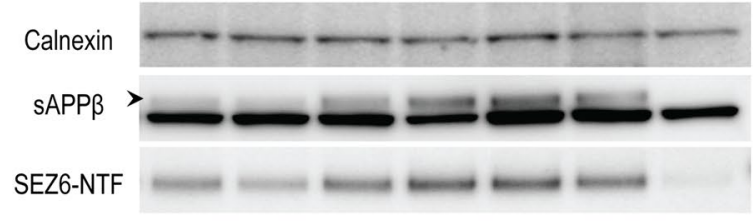

CHL1-NTF

GAPDH

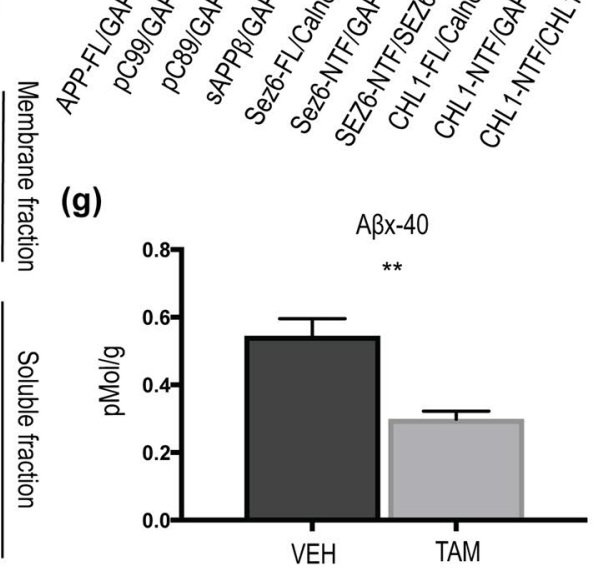

Figure 5. Axon guidance defects were absent in hippocampus mossy fibers of aged BACE1 cKO mice following partial BACE1 deletion. (a) Coronal sections collected from aged mice were stained with anti-synaptoporin (SPO) antibody (green) and DAPI (blue). Scale bar $50 \mu \mathrm{m}$. (b) Quantification of IPB length showed no alteration in TAM-treated mice compared to controls. IPB length was normalized on the length of the CA3 stratum lucidum (VEH $n=8$; TAM $n=7,3$ to 4 sections per mouse). (c) Representative microscopy images showing reduced BACE1 (D10E5) expression in the hippocampus of TAM-treated mice. BACE1 signal was totally absent in $\mathrm{BACE}^{-1-}$ mice, used as control to evaluate the amount of background in the staining. Scale bar $200 \mu \mathrm{m}$. Hippocampus full homogenates from TAM- or VEH-treated mice were resolved by SDS-PAGE for analysis of APP processing and fractionated (soluble and membrane fractions) for the analysis of SEZ6 and CHL1 processing. Homogenates from aged-matched $\mathrm{BACE}^{+/-}$and $\mathrm{BACE} 1^{-1-}$ were loaded as control samples. Representative blots of (d) APP-FL (C1/6.1) and APP- CTFs (C1/6.1), (e) fractionation blots of sAPP $\beta$ (BAWT), SEZ6 (14E5) and CHL1 (AF2147). (f) Densitometry analysis of protein expression. APP processing was reduced in TAM-treated mice as demonstrated by the accumulation of APP-FL (C1/6.1), and reduced levels of the $\beta$ CTFs pC99 and pC 89 , and sAPP $\beta$. $\beta$ CTFs and sAPP $\beta$ were identified because missing in the $\mathrm{BACE}^{-1-}$ sample. SEZ6 processing was decreased in TAM-treated mice with accumulation of the full length and decreased levels of the ectodomain (SEZ6-NTF) as well as decreased SEZ6-NTF/SEZ6FL ratio. Processing 
of CHL1 was also impaired as showed by increased of CHL1-FL levels, while CHL1-NTF was not altered. CHL1-NTF/CHL1-FL ratio was significantly decreased. APP-FL, CTFs, SEZ6-NTF and CHL1-NTF were normalized to GAPDH (MAB374), SEZ6-FL and CHL1-FL were normalized to Calnexin (610523) (VEH n =5; TAM $n=5$ ). (g) A $\beta x-40$ was quantified from hippocampus homogenates by MSD immunoassay. TAM-treated group displayed a significant reduction of $\mathrm{A} \beta \mathrm{x}-40$ levels ( $~ 50 \%$ decrease) compared to control (VEH $\mathrm{n}=7$; TAM $\mathrm{n}=7$ ). Results were plotted as Mean \pm SEM, ** $\mathrm{p}<0.005 ; * * * \mathrm{p}<0.001 ; \mathrm{n} . \mathrm{s} .=$ not significant, Student's $\mathrm{t}$ test. DG: dentate gyrus, IPB: infrapyramidal bundle, slu: stratum lucidum, MB: main bundle.

\section{Discussion}

Emerging data from the literature indicate that a near total BACE1 deletion in adult mice induces alterations such as axonal guidance and LTP defects raising concerns for negative impacts on cognitive function under high levels of BACE inhibition achieved in clinical trials ${ }^{29,30}$. We hypothesized that a partial BACE1 deletion may be able to achieve meaningful reductions in CNS A $\beta$ levels without eliciting deleterious phenotypes observed in previous models BACE1KO models.

To investigate the impact of BACE1 partial depletion on brain function we developed a unique cKO model that mimics partial BACE1 inhibition. TAM-treated BACE1 $1^{\text {flox/flox }}$;RosaCreERT2 ${ }^{+/ \mathrm{WT}}$ mice were analysed at young and old age, i.e. after short-term BACE1 depletion, or long-term BACE1 protein depletion. Though the degree of BACE1 decrease varied by brain region, the reduction was stable over time (Fig. 1c,e) mimicking a sustained level of $\mathrm{A} \beta$ lowering described for once daily dosing of verubecestat in $\mathrm{AD}$ patients $\mathrm{s}^{31}$. The observed differences in recombination efficiency across different brain areas, are most likely due to variable tissue penetration of $\mathrm{TAM}^{32}$. At both young and old ages, processing of multiple validated BACE1 substrates was reduced (CHL1-NTF/CHL1-FL: 30-40\% reduction in cortex of young and aged mice, $\sim 40 \%$ reduction in hippocampus of aged mice, SEZ6-FL/sSEZ6: $\sim 70 \%$ reduction in hippocampus of aged mice). Moreover a $50 \%$ reduction of $\mathrm{A} \beta \mathrm{x}-40$ levels were detected in both cortex and hippocampus (Figs. 2, 3 and 5), while sAPP $\beta$ levels were almost undetectable in hippocampus of aged mice ( $~ 90 \%$ reduction) (Fig. 5e,f). A direct correlation between A $\beta$ and sAPP $\beta$ levels is expected when A $\beta 1-40$ is measured. However, there is no commercially A $\beta$ ELISA A $\beta$ 1-40 for rodent is available. Thus, the difference in levels of A $\beta$ and sAPP $\beta$ inhibition that we observed is most likely due to both the detection of $\mathrm{N}$-terminally truncated $\mathrm{A} \beta$ peptides generated in absence of $\mathrm{BACE} 1^{33,34}$ and the reduced sensitivity of detecting $\operatorname{sAPP} \beta$ via western blotting.

To better characterize the impact of partial BACE1 depletion, we investigated phenotypes shown to be altered in $\mathrm{BACE}^{-1-}$ mice. We quantified sciatic nerve myelination, and we found no deficit (Fig. 4) consistent with this phenotype arising from a developmental role of BACE $1^{13}$. It is controversial whether BACE1 activity facilitates or delays remyelination events after nerve crush in adult mice ${ }^{35,36}$ and we cannot exclude that BACE1 inhibition might have consequences on remyelination events following injury in humans.

We then evaluated hippocampal structure and function phenotypes such as axon guidance and LTP. Previous studies identified axon guidance defects in the hippocampus of $\mathrm{BACE}^{-1-}$ mice $^{12}$ and in BACE1cKO mice following $90-95 \%$ depletion in adult mice ${ }^{19}$. In our experimental design we retained $~ 50 \%$ expression of BACE1 in hippocampus of aged TAM-treated mice, and no axon guidance deficit was observed (Fig. 5a,b). Although the mechanism leading to disorganization of IPB in BACE1 ${ }^{-1-}$ mice has not been elucidated, BACE1-mediated processing of CHL1 was hypothesized to be required for proper axon guidance in the dentate gyrus. In our experimental model, CHL1-FL accumulated, however, CHL1-NTF levels were not affected in TAM-treated mice compared to controls (Fig. 5e,f). The change in $\mathrm{CH}^{-} \mathrm{L} 1-\mathrm{NTF}$ suggests that additional sheddases (e.g. ADAM family) may substitute for BACE1-mediated cleavage. Thus, our data demonstrates that $50 \%$ depletion of BACE1 does not elicit axon guidance deficits in dentate gyrus. It will be important to determine if varying degrees of pharmacological inhibition of BACE1 from $\sim 50 \%$ to $>90 \%$ have similar profiles.

Measurements of the LTP response in Schaffer collateral-CA1 synapses revealed LTP impairment in aged TAM-treated mice (Fig. 6). However, PPr was not affected at $100 \mathrm{~ms}$ interstimulus interval (ISI) in TAM-treated mice, indicating that the synaptic vesicle release probability was not impaired at this ISI. These data support the hypothesis that BACE1 modulates synaptic plasticity in adulthood. Dose-dependent LTP deficits in CA1 were previously reported in mice treated with BACE inhibitors, these deficits were associated with a reduction in spine density in the layer $\mathrm{V}$ pyramidal neurons in the somatosensory cortex ${ }^{27,37}$. However it is controversial whether BACE1 cKO display LTP deficit, Hu et al. observed reduced LTP following almost total BACE1 depletion in adult mice ${ }^{20}$ while LTP was reported to be normal in a separate BACE1 cKO where TAM treatment achieved $90 \%-95 \%$ reduction in BACE1 over 9 months ${ }^{19}$. BACE1 is located at both pre- and post-synaptic terminals ${ }^{38,39}$ and its substrates support both dendritic and axonal function. For example, SEZ6 is exclusively processed by BACE1 in mice and is required for normal dendritic arborization. SEZ6 null mice display reduced spine density and increased dendritic branching in cortical neurons ${ }^{40}$. In addition, it has been shown that chronic pharmacological inhibition of BACE impairs LTP in CA1 neurons in wild type but not in SEZ6 null mice, suggesting that BACE1-mediated processing of SEZ6 is required for synaptic plasticity ${ }^{8}$. Moreover, BACE1 can modulate axonal guidance and growth cone collapse that may be related to the processing of CHL1 $1^{11,12,41}$. Taken together, these studies demonstrate the role of BACE1 in maintaining both dendritic and axonal morphology and function. Further studies are required to determine whether the LTP deficit observed here in BACE1 CKO TAM-treated mice could be associated with an alteration of axons and/or dendritic spines in CA1 or whether mossy fiber LTP is also affected. Despite the presence of an LTP deficit, no cognitive or behavioural alterations were observed in BACE1 cKO TAM-treated mice in the test that we investigated (Fig. 7).

Our study has some limitations and some questions remain to be addressed. In our model $\sim 50 \%$ to $\sim 70 \%$ $\mathrm{BACE} 1$ protein reduction resulted in an $\sim 50 \%$ decrease of $\mathrm{A} \beta \mathrm{x}-40$ in cortex and hippocampus, it remains to be 
(a)
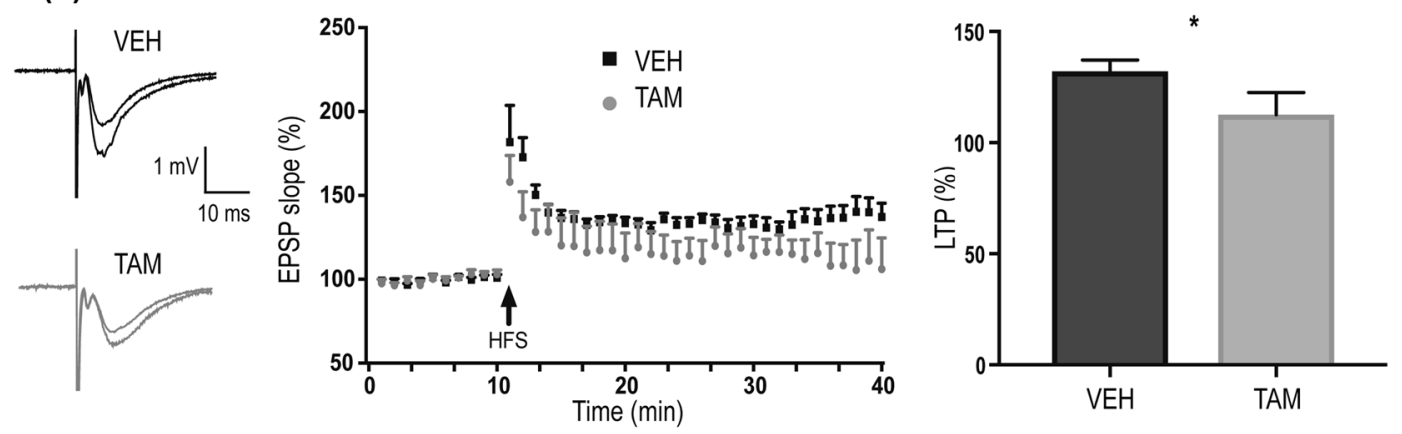

(b)
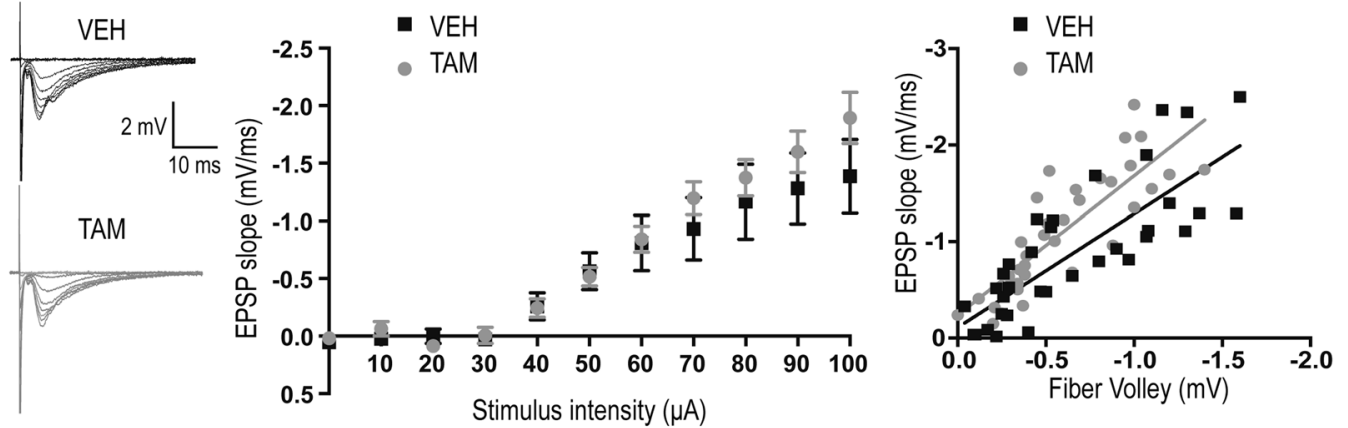

(c)
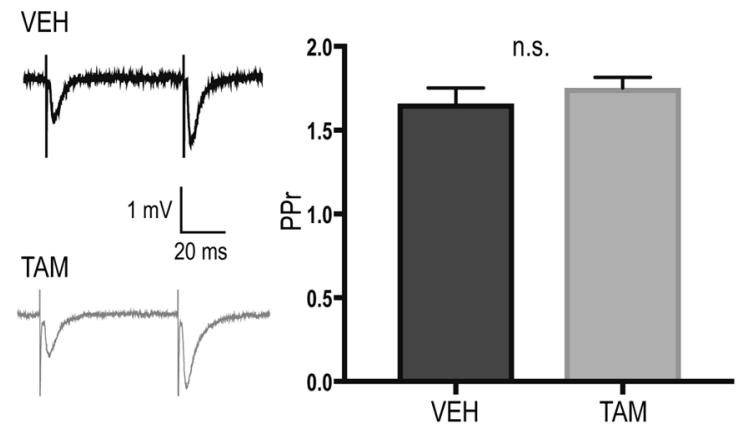

Figure 6. LTP deficit is induced in aged BACE1 cKO mice following partial BACE1 depletion. (a) Left: Representative traces for VEH and TAM-treated mice at baseline and after high frequency tetanic stimulation (HFS). Middle: Time course of normalized fEPSP slopes to the mean slope recorded during $10 \mathrm{~min}$ period before high-frequency tetanic stimulation (HFS), values were shown as average per minute for clarity. Right: The extent of LTP was calculated as a percentage of the baseline in the last $10 \mathrm{~min}$ of recording (VEH: $135.6 \pm 6.928 \%, \mathrm{n}=10$ from 4 mice; TAM: $112.5 \pm 10.09 \%, \mathrm{n}=8$ from 4 mice; $\mathrm{p}<0.05)$. (b) Left: Representative traces of fEPSPs generated by gradually increasing stimulus intensity for VEH (black) and TAM (gray) treated mice. Middle: Input-output curve of fEPSP slope versus stimulus intensity. No differences were observed between the two groups (VEH and TAM: $\mathrm{n}=5$ slices from 2 mice). Right: Input-output curve relating the slope of the fEPSP to the presynaptic fiber volley amplitude, each point represents data from individual slices. No significative statistically differences were found, (VEH and TAM: $n=5$ slices from 2 mice; $p=0.272$ ). (c) Representative traces of fEPSPs recorded in CA1, in response to Schaffer collateral paired-pulse stimuli at $100 \mathrm{~ms}$ interstimulus interval (ISI) for VEH (black trace) and TAM (gray trace) treated mice. Bar graph showed facilitation ratio for the two conditions. No significative statistically differences were found (VEH: $1.66 \pm 0.092$, $\mathrm{n}=8$ slices from 2 mice; TAM: $1.753 \pm 0.063, \mathrm{n}=9$ slices from 2 mice; $\mathrm{p}=0.357$ ). Data were plotted as mean \pm SEM. $*$ p $<0.05 ;$ ns $=$ not significant. Mann-Whitney U-test.

determined if this reduction in $A \beta$ would be enough to reverse amyloid plaque deposition, this can be achieved by crossing BACE1 cKO mice with murine models of AD or chronically administering a BACE inhibitor at $\leq \mathrm{ED}_{50}$. Studies from human genetics identified a mutation in the coding region of APP (A673T) in an Icelandic family that is protective against $\mathrm{AD}$ and cognitive decline ${ }^{42}$. This genetic variant results in decreased BACE1 processing of APP and reduced aggregation of $A \beta 42^{43}$. Plasma concentration of $A \beta 40$ and $A \beta 42$ in carriers of the A673T variant, were shown to be $\sim 28 \%$ lower compared to controls ${ }^{44}$. These data demonstrate that a small reduction of $\mathrm{A} \beta$ throughout a life span is associated with protection against $\mathrm{AD}$, suggesting that low level BACE1 inhibition could be useful as a long-term therapeutic approach. 
- VEH male

(a)

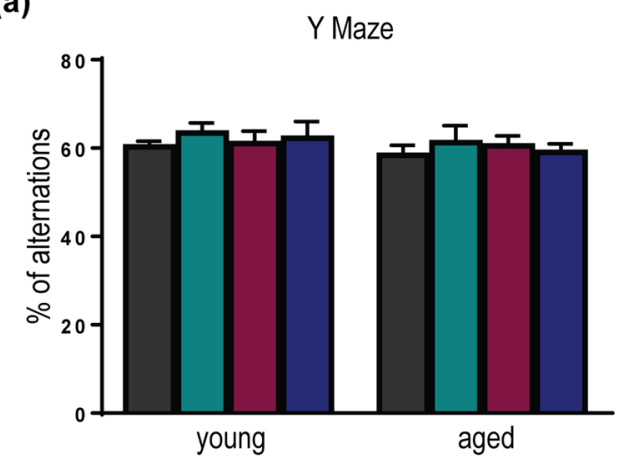

(c)

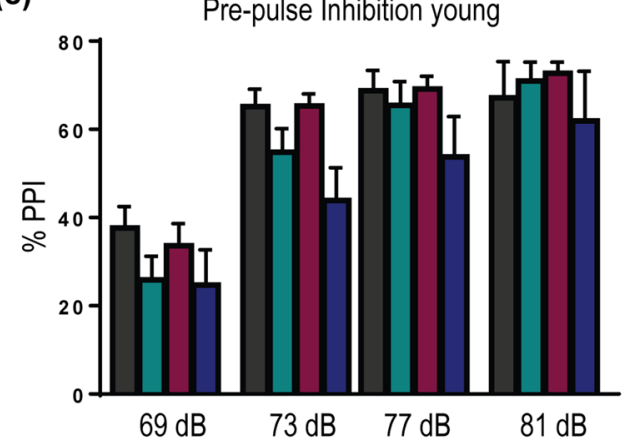

(e)

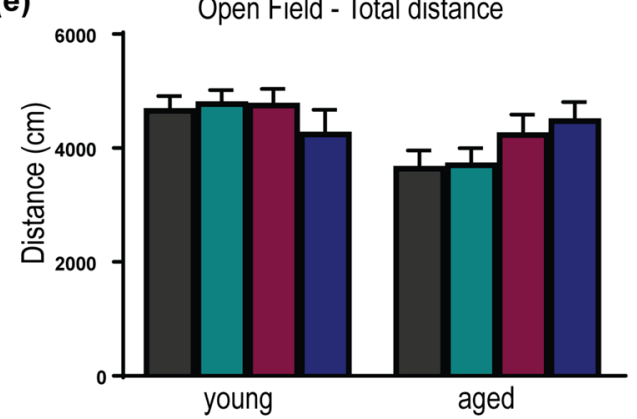

(g)

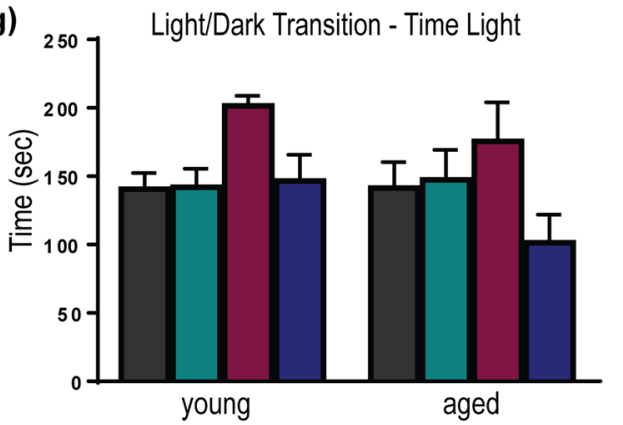

घ VEH female $\square$ TAM female

(b)

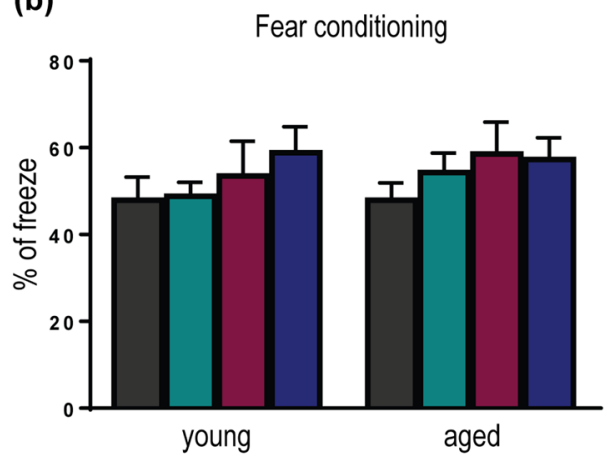

(d)

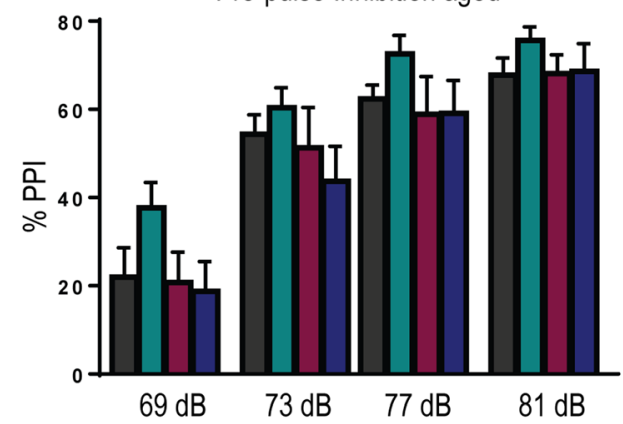

(f) Open Field - Time in center

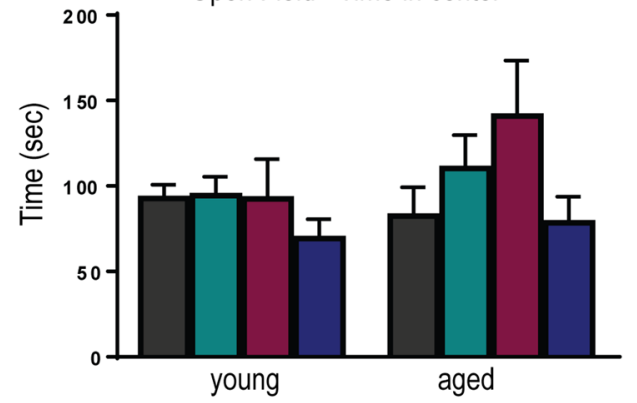

Figure 7. No behavioural deficits were detected in young and aged cKO mice following partial BACE1 deletion. TAM- or VEH-treated mice were subjected to a panel of behavioural tasks at 4-5 month-old (young). After aging, the same cohorts of mice were tested again at 12-13 months of age (aged) in the same set of behavioural tasks. Spontaneous alternation memory was investigated by Y maze task (a), while hippocampal dependent contextual memory was investigated by the contextual fear-conditioning paradigm (b). No memory deficit was detected in the investigated tasks. Pre-pulse Inhibition was performed to investigate the suppression of the acoustic startle response, both young (c) and aged mice (d) behaved normally. Open Field task showed no effect of the treatment in the total distance travelled (e), although the 3-way ANOVA analysis revealed a sex difference. Time spent in the center of the arena was also plotted to investigate anxiety phenotype, although a trend in TAM-treated females was observed at both ages, the data did not reach statistical significance (f). To further investigate the anxiety-like phenotype mice were subjected to the light/dark transition task, no difference was detected in the time spent exploring the lit compartment (g). Data were plotted as mean $\pm \mathrm{SEM}$. Analysis was 
performed by 3-way ANOVA repeated measure (time, treatment and sex used as independent variables), when no sex difference was detected male and female mice were pooled together and data were analysed by 2 -way repeated measure ANOVA (time and treatment used as independent variables). See Supplementary Table 1 for $\mathrm{p}$ values (VEH male $\mathrm{n}=13$, TAM male $\mathrm{n}=14$, VEH female $\mathrm{n}=6$, TAM female $\mathrm{n}=7$ ).

To summarize, we achieved a partial genetic depletion of BACE1 that mimics an intermediate pharmacological inhibition, we demonstrated that most of the phenotypes observed in $\mathrm{BACE}^{-1-}$ mice and in $\mathrm{BACE} 1 \mathrm{cKO}$ after complete depletion of BACE1 are absent, however, an LTP deficit is still present when decreasing BACE1 expression to $50 \%$. Importantly the deficit in LTP did not elicit behaviour impairments.

Previous studies in cKO mice demonstrated that an almost total BACE1 deletion could elicit adverse phenotypes, notably in the hippocampus. Although it is difficult to predict how the results obtained in animal models (axon guidance deficit, LTP) will translate to humans, however findings in BACE1 cKO mice suggest that high levels of BACE inhibition might have adverse effect on hippocampal functions such that any benefits coming from the $A \beta$ decrease might be masked by adverse effects due to BACE1 inhibition during clinical trials.

Clinical trials based on the BACE inhibitor verubecestat (EPOCH and APECS) were recently discontinued $^{29,30}$. As a result of verubecestat treatment, $60 \%(12 \mathrm{mg})$ to $75 \%(40 \mathrm{mg})$ average reduction of $A \beta$ in cerebrospinal fluid was observed in association with regression of amyloid PET SUVR indicating that verubecestat was effective in lowering A $\beta$ levels. However, a modest worsening of cognitive function was observed in prodromal $\mathrm{AD}$ subjects after 13 weeks of treatment with the inhibitors compared to placebo group. The cognitive impairment did not progress across the remainder of the 2-year trial period suggesting it may reflect an adaptive response due to chronic BACE inhibition. Similar findings were recently reported on the clinical trial of atabecestat in early $\mathrm{AD}^{45}$. More recently, Biogen and Eisai discontinued two phase III clinical trials (Mission AD1 and AD2, in $\mathrm{MCI}$ and early $\mathrm{AD}$ patients, respectively) with $\mathrm{BACE}$ inhibitor elenbecestat due to unfavorable risk-benefit ratio. Our findings suggest that BACE1 inhibition to a lower extent than currently under investigation should be performed to preserve BACE1-mediated process of substrates involved in synaptic plasticity. The study of cKO mice in parallel with pharmacological BACE inhibition in animal models will facilitate the understanding of the mechanism(s) underlying the cognitive worsening observed in AD patients treated with BACE inhibitors, distinguish between BACE1-dependent phenotypes and off-target effects and finally improve drug dosing for future clinical applications.

\section{Materials and Methods}

Animals. BACE1 $1^{\text {flox/flox }}$ mice (Supplementary Fig. 1a), kindly provided by Matthew Kennedy and Thomas Rosahl at Merck \&Co. Inc. were crossed with RosaCreERT2 ${ }^{+/+}$mice (Jackson Laboratory, Stock No: 008463) to obtain mice homozygous for BACE1 floxed allele and hemizygous for the RosaCreERT2allele. BACE1 ${ }^{\text {flox/flox; }}$; RosaCreERT2 ${ }^{+/ \mathrm{WT}}$ mice were used for all the experiments (Supplementary Fig. 1b). All mice generated were housed by standard conditions with ad libitum access to food and water. For Western blots, serial fractionation, Elisa and Real-Time quantitative PCR samples were collected as follow, mice were anesthetized with isoflurane and euthanized by vertebral dislocation. Cortex, hippocampus and cerebellum were dissected and snap frozen in liquid nitrogen. Samples were stored at $-80^{\circ} \mathrm{C}$ until use. All experimental procedures were approved by Tufts University Institutional Animal Care and Use Committees in accordance with US National Institutes of Health guidelines.

Tamoxifen administration. Tamoxifen (Sigma) was dissolved in sunflower oil (Sigma) at a final concentration of $20 \mathrm{mg} / \mathrm{ml}$. Animals were injected with a daily dose of $200 \mathrm{mg} / \mathrm{kg}$ per body weight of tamoxifen for 3 non-consecutive weeks (Fig. 1a). Mice were monitored and if adverse effects became apparent treatment was stopped.

Western Blots and serial fractionation. Immunoblot and serial fractionation were performed as previously described ${ }^{46}$ with the following antibodies: rabbit monoclonal anti-BACE1 (1:1000; D10E5; Cell signaling technology); mouse monoclonal anti-APP (and APP CTFs) antibody (1:5000; C1/6.1; BioLegend); goat polyclonal anti-N-terminal CHL1 antibody (for CHL1-FL and CHL1-NTF) (1:1000; AF2147; R\&D Systems); mouse monoclonal anti-GAPDH (1:10,000; MAP374; Millipore); mouse monoclonal anti- $\beta$-tubulin (1:10,000; JDR.3BR; Sigma); mouse monoclonal anti-calnexin (1:2000; 610523; BD biosciences); rabbit polyclonal anti-ADAM10 (1:1000;AB19026; Millipore); rabbit polyclonal anti-PS1 AB14 (1:1000) $)^{47}$ and rat monoclonal anti-SEZ6 $(1: 250)^{25}$, rat monoclonal anti-APPs $\beta(1: 40)^{48}$ and HRP-conjugated secondary antibodies visualized by ECL (GE Healthcare). Chemiluminescent signal was captured on an LAS4000 Fuji Imager. Densitometry analysis was performed using Quantity One software (Bio-Rad Laboratories).

Real-time quantitative PCR. Total RNA was extracted using RNAeasy Mini kit (Qiagen) subjected to reverse transcription with QuantiTect Reverse Transcription kit (Qiagen), according to manufacturer's instructions. RNA was analysed with the Agilent 2100 Bioanalyzer (Agilent Technologies). Reverse transcription reaction was amplified using the SYBR Green PCR Master Mix kit (Life Technologies) in a MX3000p qPCR System (Agilent Technologies). Primers were used were: BACE1 (Primer Bank ID: 225543121c1) and GAPDH (Primer Bank ID: 6679937a1). Relative expression levels were determined according to the $\Delta \Delta$ CT method.

A $\beta$ x-40 quantification. Homogenates in RIPA buffer were quantified by ELISA Kit Wako (Catalog \#29462501, Fujifilm Wako Pure Chemicals Corporation) or Meso Scale Discovery platform (V-PLEX Plus A $\beta$ peptide 4G8 Kit, Meso Scale Diagnostics) according to manufacturer's instruction. 
Histology. Mice were anesthetized with isoflurane, perfused intracardially with ice-cold PBS followed by $50 \mathrm{ml}$ of ice-cold $4 \%$ PFA. Brains were post fixed over night at $4{ }^{\circ} \mathrm{C}$ in $4 \%$ PFA, washed in PBS and incubated in cryoprotectant solution (30\% sucrose, $1 \%$ Polyvinyl-pyrrolidone-40, $0.05 \mathrm{M}$ phosphate buffer, $30 \%$ ethylene glycol) for at least 48 hours. Coronal sections $40 \mu \mathrm{m}$ thick were cut using a sliding microtome and stored in cryoprotectant solution. 3 to 4 sections per mouse $(\mathrm{VEH} \mathrm{n}=8$; TAM $\mathrm{n}=7$ ) at anterior/posterior coordinate spanning from -1.5 to -2.5 from Bregma were selected for IPB analysis. Sections were washed in PBS, then blocked in $5 \%$ BSA $+0.25 \%$ of Triton-X 100 and incubated with the following antibodies: anti-synaptoporin (102003, 1:500, Synaptic Systems) anti-BACE1 (D10E5, 1:1000, Cell signaling technology), anti-rabbit Alexa Fluor 488 (Life Technologies). Fluorescent images were acquired on BZ-X700 all-in-one fluorescence microscope (Keyence). Images from SPO staining were used for IPB length quantification with Fiji software (Image J) $)^{49}$. IPB length was normalized on $\mathrm{MB}+$ slu length.

For immunohistochemistry sections were washed with peroxidase blocking solution $(3 \% \mathrm{H} 2 \mathrm{O} 2,1 \% \mathrm{MetOH}$ in PBS), blocked with Superblock (Pierce) and incubated with the primary antibody (anti-BACE1 EPR3956, 1:250, Abcam). The next day sections were washed with PBS, incubated with anti-rabbit biotinylated secondary antibody (1:500, Vector Labs, Burlingame), then incubated with ABC complex (Vector Labs, Burlingame) and developed with DAB (Sigma).

G-ratio quantification in sciatic nerve. Sciatic nerves were perfused with $4 \%$ PFA/PBS, immersion fixed in $4 \%$ glutaraldehyde/PBS overnight, embedded in EPON resin and examined using a JEOL JEM-1011 transmission electron microscope with AMTv601 software (Advanced Microscopy Techniques). Tissue processing and TEM were conducted in the laboratory of Dr. Marian DiFiglia by Erin Jones (Massachusetts General Hospital, Department of Neurology, Charlestown, MA). G-ratio quantification was performed with Fiji software (Image J) $)^{49}$.

Electrophysiological recording. Coronal hippocampal slices were prepared from 14 month-old BACE1 $1^{\text {flox } /}$ ${ }_{\text {flox}}$ RosaCreERT2 $2^{+/ W T}$ as described previously ${ }^{50}$. Schaffer collaterals were electrically stimulated at $0.05 \mathrm{~Hz}$ with a concentric tungsten electrode placed in the stratum radiatum. Evoked field excitatory postsynaptic potentials (fEPSPs) were recorded using a glass electrode (2-4 M $\Omega$ ) filled with aCSF and placed in the stratum radiatum. For characterization of basal synaptic transmission, fEPSPs, generated by gradually increasing stimulus intensity, were recorded. For LTP experiments, after a stable fEPSP had been recorded for at least $10 \mathrm{~min}$ (using a response about $50 \%$ of the maximum), LTP was induced with three trains of $100 \mathrm{~Hz}$ for $1 \mathrm{~s}$ with an intertrain interval of 20 s. Data were collected and analysed using pCLAMP 9 software (Molecular Devices).

Behaviour. All behavioural testing was conducted in the Tufts University Center for Neuroscience Research (CNR) Circuits and Behavior Core Facility. A total number of 21 TAM-treated mice (14 males, 7 females) and 19 VEH-treated mice (13 males, 6 females) were subjected to a battery of behavioural tests at two different time points [4-5 month-old (young) and 12-13 month-old (aged)]. The tests were performed from the least stressful test to the more stressful one in the following order: open field, light/dark transition, Y-maze, pre-pulse inhibition (PPI) and contextual fear conditioning. Chambers were thoroughly cleaned with 70\% ETOH between test subjects. Open field, light/dark transitions and contextual fear conditioning were performed as previously described $^{51}$.

Y-maze. Mice were placed in the starting arm and given $8 \mathrm{~min}$ to freely explore and recorded using EthoVision ${ }^{\circledR}$ XT10 (Noldus Information Technology). The correct sequential triad (e.g., ABC) entry into all three arms of the y-maze was classified as a 'correct alternation event' whereas an incorrect sequential triad (e.g., ABA) was classified as 'incorrect alternation event'. All data were reported as \%alternation.

Pre-pulse inhibition (PPI). Animals were tested for PPI using the Startle Monitor System (Kinder Scientific). The startle chamber (inner dimensions: $27 \mathrm{~L} \times 17 \mathrm{~W} \mathrm{~cm} \times 28 \mathrm{H} \mathrm{cm}$ ) consisted of a speaker (diameter $7 \mathrm{~cm}$ ) mounted on the top the chamber pointing down and a piezoelectric sensing platform on the floor. During testing, animals were placed in an adjustable holder $(9 \mathrm{~L} \times 4 \mathrm{~W} \times 3.5 \mathrm{H} \mathrm{cm})$ positioned atop the sensing platform, providing only limited restraint while prohibiting ambulation. Animals were allowed a $5 \mathrm{~min}$ acclimation period prior to the onset of acoustic stimuli. A continuous 65 dBA broadband ("white") background noise was present during the acclimation period and throughout the experiment. Two trial types were used in the experiment: basic startle stimulus of $40 \mathrm{mS}, 120 \mathrm{dBA}$ broad band noise pulse, and a pre-pulse stimuli consisting of several $40 \mathrm{mS}, 65,69$, 73,77 , and $81 \mathrm{dBA}$ pre-pulses that preceded the basic startle stimulus by $120 \mathrm{mS}$. No stimulus trials were also included. These two stimulus trial types are referred to herein as pulse and pre-pulse trials, respectively. Each animal received 72 stimuli presented in pseudorandom order with a pseudorandom interstimulus interval (range $7-23 \mathrm{sec}$ ). The first and last 6 trials consisted of a $120 \mathrm{dBA}$ pulse stimuli to provide a baseline startle response. Whole body startle responses were recorded in Newtons. The percent of PPI expressed within each test session was calculated as follows: $[100-($ mean pre-pulse response/mean pulse response $) \times 100)]$.

Statistical analysis. Data from the biochemical and immunohistochemistry studies were analysed by two-tailed Student's t-tests. Data from G-ratio quantification were analysed with Mann-Whitney test (to detect difference between medians) and Kolmogorov-Smirnov test (to check for significant difference in the distribution). Input output curve was analysed by 2 -way ANOVA, EPSP vs fiber volley curves were analysed by linear regression and LTP was analysed by Mann-Whitney U-test.

Behavioural studies were analysed with 3-way repeated measure ANOVAs (time, treatment and sex as independent variables). When no sex-treatment interactions were detected, male and female mice were pooled and 2-way repeated measures ANOVAs were performed (time and treatment as independent variables). A sex 
difference was observed for the distance travelled in the open field, in this case male and female mice were analysed separately using a 2-way ANOVA with time and treatment as independent variables. Statistical analysis was performed with GraphPad PRISM software, v. 7 (GraphPad Software).

\section{Data availability}

The datasets generated during and analysed during the current study are available from the corresponding author on reasonable request.

Received: 28 August 2019; Accepted: 10 December 2019;

Published online: 27 December 2019

\section{References}

1. Hong, L. et al. Structure of the protease domain of memapsin 2 (beta-secretase) complexed with inhibitor. Science 290, 150-153 (2000).

2. Hussain, I. et al. Identification of a novel aspartic protease (Asp 2) as beta-secretase. Mol Cell Neurosci 14, 419-427, https://doi. org/10.1006/mcne.1999.0811 (1999).

3. Lin, X. et al. Human aspartic protease memapsin 2 cleaves the beta-secretase site of beta-amyloid precursor protein. Proc Natl Acad Sci USA 97, 1456-1460 (2000).

4. Sinha, S. et al. Purification and cloning of amyloid precursor protein beta-secretase from human brain. Nature 402, 537-540, https:// doi.org/10.1038/990114 (1999).

5. Vassar, R. et al. Beta-secretase cleavage of Alzheimer's amyloid precursor protein by the transmembrane aspartic protease BACE. Science 286, 735-741 (1999).

6. Yan, R. et al. Membrane-anchored aspartyl protease with Alzheimer's disease beta-secretase activity. Nature 402, 533-537, https:// doi.org/10.1038/990107 (1999).

7. Hsiao, C. C., Rombouts, F. \& Gijsen, H. J. M. New evolutions in the BACE1 inhibitor field from 2014 to 2018. Bioorg Med Chem Lett 29, 761-777, https://doi.org/10.1016/j.bmcl.2018.12.049 (2019).

8. Zhu, K., Peters, F., Filser, S. \& Herms, J. Consequences of Pharmacological BACE Inhibition on Synaptic Structure and Function. Biol Psychiatry 84, 478-487, https://doi.org/10.1016/j.biopsych.2018.04.022 (2018).

9. Yan, R. \& Vassar, R. Targeting the beta secretase BACE1 for Alzheimer's disease therapy. Lancet Neurol 13, 319-329, https://doi. org/10.1016/S1474-4422(13)70276-X (2014).

10. Das, B. \& Yan, R. A Close Look at BACE1 Inhibitors for Alzheimer's Disease Treatment. CNS Drugs 33, 251-263, https://doi. org/10.1007/s40263-019-00613-7 (2019)

11. Rajapaksha, T. W., Eimer, W. A., Bozza, T. C. \& Vassar, R. The Alzheimer's beta-secretase enzyme BACE1 is required for accurate axon guidance of olfactory sensory neurons and normal glomerulus formation in the olfactory bulb. Mol Neurodegener 6, 88, https:// doi.org/10.1186/1750-1326-6-88 (2011).

12. Hitt, B. et al. beta-Site amyloid precursor protein (APP)-cleaving enzyme 1 (BACE1)-deficient mice exhibit a close homolog of L1 (CHL1) loss-of-function phenotype involving axon guidance defects. J Biol Chem 287, 38408-38425, https://doi.org/10.1074/jbc. M112.415505 (2012).

13. Willem, M. et al. Control of peripheral nerve myelination by the beta-secretase BACE1. Science 314, 664-666, https://doi. org/10.1126/science.1132341 (2006).

14. Hu, X. et al. Bace1 modulates myelination in the central and peripheral nervous system. Nat Neurosci 9, 1520-1525, https://doi. org/10.1038/nn1797 (2006).

15. Hu, X., He, W., Luo, X., Tsubota, K. E. \& Yan, R. BACE1 regulates hippocampal astrogenesis via the Jagged1-Notch pathway. Cell Rep 4, 40-49, https://doi.org/10.1016/j.celrep.2013.06.005 (2013).

16. Savonenko, A. V. et al. Alteration of BACE1-dependent NRG1/ErbB4 signaling and schizophrenia-like phenotypes in BACE1-null mice. Proc Natl Acad Sci USA 105, 5585-5590, https://doi.org/10.1073/pnas.0710373105 (2008).

17. Laird, F. M. et al. BACE1, a major determinant of selective vulnerability of the brain to amyloid-beta amyloidogenesis, is essential for cognitive, emotional, and synaptic functions. J Neurosci 25, 11693-11709, https://doi.org/10.1523/JNEUROSCI.2766-05.2005 (2005).

18. Ohno, M. et al. BACE1 deficiency rescues memory deficits and cholinergic dysfunction in a mouse model of Alzheimer's disease. Neuron 41, 27-33 (2004).

19. Ou-Yang, M. H. et al. Axonal organization defects in the hippocampus of adult conditional BACE1 knockout mice. Sci Transl Med, 10, https://doi.org/10.1126/scitranslmed.aao5620 (2018)

20. Hu, X., Das, B., Hou, H., He, W. \& Yan, R. BACE1 deletion in the adult mouse reverses preformed amyloid deposition and improves cognitive functions. J Exp Med 215, 927-940, https://doi.org/10.1084/jem.20171831 (2018).

21. Ventura, A. et al. Restoration of p53 function leads to tumour regression in vivo. Nature 445, 661-665, https://doi.org/10.1038/ nature05541 (2007).

22. Vassar, R. BACE1 inhibitor drugs in clinical trials for Alzheimer's disease. Alzheimers Res Ther 6, 89, https://doi.org/10.1186/s13195014-0089-7 (2014).

23. Kuhn, P. H. et al. Secretome protein enrichment identifies physiological BACE1 protease substrates in neurons. EMBO J 31, 3157-3168, https://doi.org/10.1038/emboj.2012.173 (2012).

24. Montag-Sallaz, M., Schachner, M. \& Montag, D. Misguided axonal projections, neural cell adhesion molecule 180 mRNA upregulation, and altered behavior in mice deficient for the close homolog of L1. Mol Cell Biol 22, 7967-7981 (2002).

25. Pigoni, M. et al. Seizure protein 6 and its homolog seizure 6-like protein are physiological substrates of BACE1 in neurons. Mol Neurodegener 11, 67, https://doi.org/10.1186/s13024-016-0134-z (2016).

26. Wang, H., Song, L., Laird, F., Wong, P. C. \& Lee, H. K. BACE1 knock-outs display deficits in activity-dependent potentiation of synaptic transmission at mossy fiber to CA3 synapses in the hippocampus. J Neurosci 28, 8677-8681, https://doi.org/10.1523/ JNEUROSCI.2440-08.2008 (2008).

27. Filser, S. et al. Pharmacological inhibition of BACE1 impairs synaptic plasticity and cognitive functions. Biol Psychiatry 77, 729-739, https://doi.org/10.1016/j.biopsych.2014.10.013 (2015).

28. Ohno, M. et al. BACE1 gene deletion prevents neuron loss and memory deficits in 5XFAD APP/PS1 transgenic mice. Neurobiol Dis 26, 134-145, https://doi.org/10.1016/j.nbd.2006.12.008 (2007).

29. Egan, M. F. et al. Randomized Trial of Verubecestat for Mild-to-Moderate Alzheimer's Disease. N Engl J Med 378, 1691-1703, https://doi.org/10.1056/NEJMoa1706441 (2018).

30. Egan, M. F. et al. Randomized Trial of Verubecestat for Prodromal Alzheimer's Disease. N Engl J Med 380, 1408-1420, https://doi. org/10.1056/NEJMoa1812840 (2019).

31. Kennedy, M. E. et al. The BACE1 inhibitor verubecestat (MK-8931) reduces CNS beta-amyloid in animal models and in Alzheimer's disease patients. Sci Transl Med 8, 363ra150, https://doi.org/10.1126/scitranslmed.aad9704 (2016).

32. Ripoche, D. et al. Generation of a conditional mouse model to target Acvrlb disruption in adult tissues. Genesis 51, 120-127, https:// doi.org/10.1002/dvg.22352 (2013). 
33. Nishitomi, K. et al. BACE1 inhibition reduces endogenous Abeta and alters APP processing in wild-type mice. J Neurochem 99, 1555-1563, https://doi.org/10.1111/j.1471-4159.2006.04178.x (2006).

34. Becker-Pauly, C. \& Pietrzik, C. U. The Metalloprotease Meprin beta Is an Alternative beta-Secretase of APP. Front Mol Neurosci 9 , 159, https://doi.org/10.3389/fnmol.2016.00159 (2016).

35. Hu, X. et al. Genetic deletion of BACE1 in mice affects remyelination of sciatic nerves. FASEB J 22, 2970-2980, https://doi. org/10.1096/fi.08-106666 (2008).

36. Tallon, C. \& Farah, M. H. Beta secretase activity in peripheral nerve regeneration. Neural Regen Res 12, 1565-1574, https://doi. org/10.4103/1673-5374.217319 (2017).

37. Blume, T. et al. BACE1 Inhibitor MK-8931 Alters Formation but Not Stability of Dendritic Spines. Front Aging Neurosci 10, 229, https://doi.org/10.3389/fnagi.2018.00229 (2018).

38. Kandalepas, P. C. et al. The Alzheimer's beta-secretase BACE1 localizes to normal presynaptic terminals and to dystrophic presynaptic terminals surrounding amyloid plaques. Acta Neuropathol 126, 329-352, https://doi.org/10.1007/s00401-013-1152-3 (2013).

39. Das, U. et al. Visualizing APP and BACE-1 approximation in neurons yields insight into the amyloidogenic pathway. Nat Neurosci 19, 55-64, https://doi.org/10.1038/nn.4188 (2016).

40. Gunnersen, J. M. et al. Sez-6 proteins affect dendritic arborization patterns and excitability of cortical pyramidal neurons. Neuron 56, 621-639, https://doi.org/10.1016/j.neuron.2007.09.018 (2007).

41. Barao, S. et al. Antagonistic Effects of BACE1 and APH1B-gamma-Secretase Control Axonal Guidance by Regulating Growth Cone Collapse. Cell Rep 12, 1367-1376, https://doi.org/10.1016/j.celrep.2015.07.059 (2015).

42. Jonsson, T. et al. A mutation in APP protects against Alzheimer's disease and age-related cognitive decline. Nature 488, 96-99, https://doi.org/10.1038/nature11283 (2012).

43. Maloney, J. A. et al. Molecular mechanisms of Alzheimer disease protection by the A673T allele of amyloid precursor protein. J Biol Chem 289, 30990-31000, https://doi.org/10.1074/jbc.M114.589069 (2014).

44. Martiskainen, H. et al. Decreased plasma beta-amyloid in the Alzheimer's disease APP A673T variant carriers. Ann Neurol 82, 128-132, https://doi.org/10.1002/ana.24969 (2017).

45. Henley, D. et al. Preliminary Results of a Trial of Atabecestat in Preclinical Alzheimer's Disease. N Engl J Med 380, 1483-1485, https://doi.org/10.1056/NEJMc1813435 (2019).

46. Kim, W. et al. BACE1 elevation engendered by GGA3 deletion increases beta-amyloid pathology in association with APP elevation and decreased CHL1 processing in 5XFAD mice. Mol Neurodegener 13, 6, https://doi.org/10.1186/s13024-018-0239-7 (2018).

47. Zhang, Y. W. et al. Nicastrin is critical for stability and trafficking but not association of other presenilin/gamma-secretase components. J Biol Chem 280, 17020-17026, https://doi.org/10.1074/jbc.M409467200 (2005).

48. Ullrich, S. et al. The novel membrane protein TMEM59 modulates complex glycosylation, cell surface expression, and secretion of the amyloid precursor protein. J Biol Chem 285, 20664-20674, https://doi.org/10.1074/jbc.M109.055608 (2010).

49. Schindelin, J. et al. Fiji: an open-source platform for biological-image analysis. Nature methods 9, 676-682, https://doi.org/10.1038/ nmeth.2019 (2012).

50. Papouin, T. \& Haydon, P. G. Obtaining Acute Brain Slices. Bio Protoc, 8, https://doi.org/10.21769/BioProtoc.2699 (2018).

51. Walker, K. R. et al. Genetic Deletion of the Clathrin Adaptor GGA3 Reduces Anxiety and Alters GABAergic Transmission. PLoS One 11, e0155799, https://doi.org/10.1371/journal.pone.0155799 (2016).

\section{Acknowledgements}

This work was supported by Award Number R01NS092497 (to GT) and R01AG025952 (to GT) from National Institute of Health (NIH). We thank Erin Jones for her superb technical help and are grateful for the services of the Philly Dake EM core facility directed by Dr. Marian DiFiglia and supported by NIH/NINDS P30NS045776. We also thank Dr. S.F. Lichtenthaler who kindly provided the anti-SEZ6 (14E5) and anti-APPs $\beta$ antibody (BAWT) and Dr. S. Gandy for the anti-PS1 antibody (AB14). We are also grateful to the Circuits and Behavior Core facility at Tufts University School of Medicine for assistance with behavioral experiments.

\section{Author contributions}

S.L. and G.T. conceived the study and wrote the manuscript. S.L., M.C., A.T., W.K., T.C., G.S., W.X. performed experiments and analysed the data. T.R. and M.K provided the animal model and feedback on project. P.G.H. provided feedback on electrophysiology experiments. All authors read and approved the final manuscript.

\section{Competing interests}

S.L., M.C., A.T., W.K., T.C., G.S., W.X., P.G.H. and G.T. report no biomedical financial interests or potential conflicts of interest. M.E.K. and T.W.R. are full time employees of Merck \&Co. Inc.

\section{Additional information}

Supplementary information is available for this paper at https://doi.org/10.1038/s41598-019-56329-7.

Correspondence and requests for materials should be addressed to G.T.

Reprints and permissions information is available at www.nature.com/reprints.

Publisher's note Springer Nature remains neutral with regard to jurisdictional claims in published maps and institutional affiliations.

Open Access This article is licensed under a Creative Commons Attribution 4.0 International License, which permits use, sharing, adaptation, distribution and reproduction in any medium or format, as long as you give appropriate credit to the original author(s) and the source, provide a link to the Creative Commons license, and indicate if changes were made. The images or other third party material in this article are included in the article's Creative Commons license, unless indicated otherwise in a credit line to the material. If material is not included in the article's Creative Commons license and your intended use is not permitted by statutory regulation or exceeds the permitted use, you will need to obtain permission directly from the copyright holder. To view a copy of this license, visit http://creativecommons.org/licenses/by/4.0/.

(c) The Author(s) 2019 